\title{
Anti-Inflammatory Effect of IL-37b in Children with Allergic Rhinitis
}

\author{
Wenlong Liu, ${ }^{1}$ Li Deng, ${ }^{1}$ Yanqiu Chen, ${ }^{1}$ Changzhi Sun, ${ }^{1}$ Jie Wang, ${ }^{1}$ Lifeng Zhou, \\ Huabin $\mathrm{Li}^{2}{ }^{2}$ and Renzhong $\mathrm{Luo}^{1}$ \\ ${ }^{1}$ Department of Otolaryngology, Guangzhou Women and Children's Medical Center, Guangzhou Medical College, \\ No. 9 Jinsui Road, Guangzhou 510623, China \\ ${ }^{2}$ Department of Otolaryngology, Head and Neck Surgery, Xinhua Hospital, Shanghai Jiaotong University School of Medicine, \\ No. 1665 Kongjiang Road, Shanghai 200092, China
}

Correspondence should be addressed to Huabin Li; noseli@126.com and Renzhong Luo; 691285341@qq.com

Received 9 December 2013; Revised 4 July 2014; Accepted 14 July 2014; Published 11 August 2014

Academic Editor: Arkadiusz Orzechowski

Copyright (C) 2014 Wenlong Liu et al. This is an open access article distributed under the Creative Commons Attribution License, which permits unrestricted use, distribution, and reproduction in any medium, provided the original work is properly cited.

Background. Interleukin-37 (IL-37), a newly described member of IL-lfamily, functioned as a fundamental inhibitor of innate inflammatory and immune responses, especially its isoform IL-37b. Objective. This study was undertaken to evaluate the expression and regulation of IL-37b in children with allergic rhinitis (AR). Methods. Forty children with AR and twenty-five normal controls were included. The relationship between IL-37b and Th1/2 cytokines production in serum and nasal lavage was examined by enzyme-linked immunosorbent assay (ELISA). Peripheral blood mononuclear cells (PBMCs) were purified for in vitro regulation experiment of IL-37b. Intranasal mometasone furoate was given in AR children and IL-37b change after one-month treatment was detected using ELISA. Results. We observed significantly decreased IL-37b expression levels in both serum and nasal lavage compared to controls. IL-37b was negatively correlated with Th2 cytokines. Our results also showed that IL-37b downregulated Th2 cytokine expressed by PBMCs and this modulation was through mitogen-activated protein kinase (MAPK) and phosphatidylinositol 3-kinase (PI3K) pathway. We also found that intranasal mometasone furoate therapy can promote nasal IL-37b expression. Conclusion. IL-37b may be involved in Th2 cytokine regulation in AR and its expression was related to the efficacy of intranasal steroid therapy.

\section{Introduction}

Allergic rhinitis (AR) is a worldwide common disease in children with occurrence of $10-40 \%[1,2]$. It affects both life and performance of children and it is often accompanied by asthma [3]. T cell type-2 (Th2) inflammation accompanied by infiltration with eosinophils is characteristic pathological changes in AR $[4,5]$. Infiltration of T cells, B cells, plasma cells, eosinophils, basophils, and neutrophils and activation of Th2 cells caused the occurrence of AR [6]. Most studies about pathophysiological mechanism of AR focused on proinflammatory cytokines, while antiinflammatory cytokines received less attention.

Interleukin-37 (IL-37) is a recently discovered antiinflammatory cytokine and can bind to IL-18-receptor (R) and IL-18-binding protein (BP) [7, 8]. IL-37 can be secreted by monocytes, macrophages, epithelial cells, and so on [9]. IL-37 is expressed in normal and tumor tissues in human and it exerts anti-inflammatory effects by suppressing innate immune responses through decreasing the production of inflammatory cytokines [10]. IL-37 has five different isoforms, of which IL-37b is the largest isoform and it is believed to suppress proinflammatory cytokine production and dendritic cell (DC) activation [8]. The role of IL-37b in autoimmune diseases was well characterized recently. It was reported that IL-37b expression was elevated in rheumatoid arthritis, in patients with Mycobacterium avium infections, atherosclerotic coronary and carotid artery plaques, in psoriatic plaques, and in Crohn's disease [10, 11]. However, the role of IL-37b in allergic disease is not characterized.

In our present study, we sought to determine the expression of IL-37b in serum and nasal lavage of AR children and 
the effect of IL-37b on Th1/2 cytokines production and the involved signaling pathway.

\section{Methods}

2.1. Patients. Forty children ( $<18$ years old) with AR were recruited in the study. The diagnosis was established on history, clinical examination, skin prick test, and specific IgE measurement, which is in accordance with Allergic Rhinitis and its Impact on Asthma (ARIA) guideline (2010) [12]. Of them, children with asthma were diagnosed according to the global initiative for asthma (GINA) criteria [13]. Twenty-five children of similar age and gender with no history of allergic disease or wheezing were selected as the control group. Those with chronic diseases (e.g., malnutrition, anatomic malformation of the respiratory system, chronic lung disease, heart disease, gastroesophageal reflux disease, and cystic fibrosis) and those with a history of chronic drug use (e.g., oral or nasal corticosteroids, antiepileptics, and immune suppressives) were excluded from the study. The tissues from the inferior turbinate from nine AR children (13-17 years old) and eight controls (13-16 years old) that underwent inferior turbinectomy due to severe nasal congestion caused by inferior turbinate hypertrophy were sampled for detection.

2.2. Blood and Nasal Lavage Samples Preparation and Anal$y$ sis. Venous blood samples were collected into Vacuette tubes and centrifuged at $1000 \mathrm{~g}$ for $15 \mathrm{~min}$ at $4^{\circ} \mathrm{C}$. Serum samples were stored at $-80^{\circ} \mathrm{C}$. These samples were used for enzyme-linked immunosorbent assay (ELISA) and qPCR measurement. The whole blood cell counts were measured by LH-785 system (Beckman Coulter, Mervue, Galway, Ireland). Total serum IgE was measured by electrochemiluminescence (ECLIA) method using an ELX-800 system.

Nasal lavage was performed using saline warmed to $37^{\circ} \mathrm{C}$. The process was performed according to method described elsewhere [14]. Due to cooperation of children, $28 \mathrm{AR}$ samples and 15 controls were collected. The samples were centrifuged to remove cellular debris and aliquots of the supernatants were stored at $-20^{\circ} \mathrm{C}$ in eppendorf tubes until analysis. Total protein concentrations were determined with Bio-Rad protein assays according to Bradford [15].

2.3. ELISA for Protein Expression and ECLIA for Eosinophil Cationic Protein (ECP) Protein Expression. ELISA kits were used for measuring IL-37b, IL-4, IL-13, IL-5, IL-12, IFN- $\gamma$, and IL-10 (all from R\&D systems, USA) level in serum, nasal lavage, and supernatant of peripheral blood mononuclear cells (PBMCs). ECP levels were detected by other ELISA kit (EIAab, Wuhan, China), according to the manufacturer's protocols. The detection limits of the assays were as follows: IL-37b (125 pg/mL), IL-4 (1.56 pg/mL), IL-13 (93.8 pg/mL), IL-5 (7.8 pg/mL), IL-12 (2.5 pg/mL), IFN- $\gamma(12.5 \mathrm{pg} / \mathrm{mL})$, and IL-10 (3.9 pg/mL).

2.4. Real-Time PCR Analysis. Real-time PCR was performed as described previously [16]. Total RNA was extracted from mucosa tissues using TRIzol reagent (Life Technologies, Carlsbad, CA, USA) according to the manufacturer's instructions. Reverse transcription (RT) was performed, and cDNA was synthesized from $2 \mu \mathrm{g}$ of total RNA using an oligo (dT) 18 primer and M-MLV reverse transcriptase (TAKARA, Syuzou, Shiga, Japan). The mRNA expression was determined using an ABI PRISM 7300 Detection System (Applied Biosystems, Foster City, CA, USA) and SYBR Premix Taq (TAKARA). The sequences of the primers were as follows: IL37b, forward primer: $5^{\prime}$-CTCCTGGGGGTCTCTAAAGG-3', reverse primer: $5^{\prime}$-TACAATTGCAGGAGGTGCAG- $3^{\prime} ; \beta$ actin, forward primer: $5^{\prime}$-CAGAGCAAGAGAGGCATCCT3', reverse primer: $5^{\prime}$-GTTGAAGGTCTCAAACATGATC$3^{\prime}$; PRISM samples contained $1 \times$ SYBR Green Master Mix, $1.5 \mu \mathrm{L}$ of $5 \mu \mathrm{M}$ primers, and $25 \mathrm{ng}$ of synthesized cDNA in a $25 \mu \mathrm{L}$ volume. Reaction mixtures were heated to $95^{\circ} \mathrm{C}$ for $10 \mathrm{~min}$, followed by 40 cycles of denaturation at $95^{\circ} \mathrm{C}$ for $10 \mathrm{~s}$, and annealing extension at $60^{\circ} \mathrm{C}$ for $60 \mathrm{~s}$. All PCR reactions were performed in duplicate. Melting curve analysis was used to control for amplification specificity. The mean value of the replicates for each sample was calculated and expressed as a cycle threshold $(\mathrm{Ct})$ value. The relative expression of each target gene was determined as the difference $(\Delta \mathrm{Ct})$ between the $\mathrm{Ct}$ value of the target gene and the $\mathrm{Ct}$ value of $\beta$-actin. Fold changes in the target gene mRNA were determined as $2^{-\Delta \Delta \mathrm{Ct}}$.

2.5. Immunohistochemical (IHC) Staining. For immunohistochemistry, the slides were placed in $0.3 \% \mathrm{H}_{2} \mathrm{O}_{2}$ for 20 minutes at room temperature to reduce nonspecific background staining caused by endogenous peroxidases. After additional washing with PBS again, the slides were boiled in $10 \mathrm{mM}$ citrate buffer for 15 minutes followed by cooling at room temperature. Antibodies for IL-37b (Abcam and Creative BioMart, USA), IL-12 (R\&D systems, USA), IL-4 (R\&D systems, USA), IL-1 (R\&D systems, USA), and IgG (as control, Dako, Denmark) were incubated overnight at $4^{\circ} \mathrm{C}$ for immunohistochemical staining, respectively. The next day, the slides were washed with PBS and incubated with secondary antibody conjugated with streptavidin-horseradish peroxidase (Gene Tech, Shanghai, China) at room temperature for 1 hour.

After washing, DAB (Gene Tech, Shanghai, China) staining was performed under microscope. After rinsing with distilled water, the sections were counterstained with Mayer's hematoxylin (Zhongshan Goldenbridge, Beijing, China) for further 25 seconds, dehydrated with series of ethanol $(\mathrm{v} / \mathrm{v}$, $90 \%-100 \%$ ), cleared from lipid with xylene (3 times), and mounted with neutral balsam (Zhongshan Goldenbridge, Beijing, China). Control for nonspecific staining was routinely performed with PBS but antibody and all proved negative with secondary antibody.

The sections were blindly examined and coded with no awareness of the clinical data. They were visualized with an Olympus CX40 Microscope (Olympus Europa GmbH, Germany). The number of positive cells (brown cells) was counted in 10 high-magnification visual fields $(\times 200)$ and averaged. 
TABLE 1: Demographic characteristic of AR children and normal controls.

\begin{tabular}{|c|c|c|c|}
\hline Groups & AR without asthma group & AR with asthma group & Control \\
\hline Number & 30 & 10 & 25 \\
\hline Sex (male : female) & $16: 14$ & $6: 4$ & $12: 13$ \\
\hline Age (months) & $71.2 \pm 34.0$ & $63.2 \pm 23.0$ & $72.0 \pm 31.8$ \\
\hline History of asthma, $n(\%)$ & 0 & 100 & 0 \\
\hline Family history of atopy, $n(\%)$ & $15(50)^{*}$ & $8(80)^{\#}$ & $3(12)$ \\
\hline Exposure to smoking, $n(\%)$ & $18(60)^{*}$ & $7(70)^{\#}$ & $1(4)$ \\
\hline Eosinophil $^{\mathrm{a}}\left(\right.$ count $\left./ \mathrm{mm}^{3}\right)$ & $145(60-1350)^{*}$ & $195(60-1350)^{\#}$ & $73(5-230)$ \\
\hline Neutrophil $^{\mathrm{a}}\left(\right.$ count $\left./ \mathrm{mm}^{3}\right)$ & $8430(2000-16300)$ & $12330(9000-25700)^{\#}$ & $7400(3200-12500)$ \\
\hline Basophil $^{\mathrm{a}}\left(\right.$ count $\left./ \mathrm{mm}^{3}\right)$ & $50(10-150)^{*}$ & $160(70-350)^{\#}$ & $8(4-16)$ \\
\hline Monocytes $^{\mathrm{a}}\left(\operatorname{count} / \mathrm{mm}^{3}\right)$ & $238(70-2740)$ & $268(80-1960)$ & $256(60-2530)$ \\
\hline Lymphocyte $^{\mathrm{a}}$ (count $\left./ \mathrm{mm}^{3}\right)$ & $7900(3100-15400)$ & $7500(4100-16600)$ & $8300(2500-16300)$ \\
\hline $\mathrm{ECP}^{\mathrm{a}}(\mathrm{ng} / \mathrm{mL})$ & $38.2(4.0-131.0)^{*}$ & $68.1(35.0-188.0)^{\#}$ & $10.9(3.6-109.0)$ \\
\hline $\operatorname{IgE}^{\mathrm{a}}(\mathrm{IU} / \mathrm{mL})$ & $101.1(2.5-1200.0)^{*}$ & $198.2(87.5-1600.0)^{\#}$ & $31.0(5.3-89.0)$ \\
\hline
\end{tabular}

${ }^{\mathrm{a}}$ Data presented as median values (minimum-maximum).

${ }^{*}$ Compared with control group, $P<0.05$.

${ }^{\#}$ Compared with AR group, $P<0.05$.

2.6. PBMCs Preparation. PBMCs were separated from $20 \mathrm{~mL}$ of heparinized whole blood from AR children. Specifically, cells were isolated by Lymphoprep (Fresenius Kabi Norge AS, Oslo, Norway) density-gradient centrifugation from heparinized leucocyte-enriched buffy coats. Then, PBMCs were cultured at $2 * 10^{6} / \mathrm{mL}$ in 24 -well plates in culture medium: RPMI 1640 supplemented with 5\% human AB serum, $5 \mathrm{mmol} / \mathrm{L}$ glutamine, and penicillin, and streptomycin solution (all from Invitrogen, except for serum from SigmaAldrich). Stimulation was performed through addition of rhIL-37b (1-100 ng/mL) with or without other cytokines (Poly (I:C) (1 ng/mL), rhIL-4 (1-100 ng/mL), rhIL-5 (1-100 ng/mL), rhIL-13 (1-100 ng/mL), rhIL-12 (1-100 ng/mL), rhIFN- $\gamma$ (1$100 \mathrm{ng} / \mathrm{mL})$, rhIL-10 (1-100 ng/mL), SB203580 (10 $\mu \mathrm{mol} / \mathrm{L})$, and LY294002 $(10 \mu \mathrm{mol} / \mathrm{L})$. All the above stimulators were from R\&D systems.

\subsection{Human Peripheral Blood Eosinophil Purification and} Assay. Eosinophils were obtained from the peripheral blood of atopic donors (blood eosinophil levels 5-10\%) by MACSnegative immunomagnetic separation as described previously [17]. The purity of cells was $98-100 \%$ (Kimura staining) and the viability was larger than $98 \%$ (Trypan blue staining). The isolated eosinophils were suspended in RPMI-1640 supplemented with $10 \%$ heat-inactivated fetal calf serum (FCS), $2 \mathrm{mM}$ L-glutamine, $100 \mathrm{U} / \mathrm{mL}$ penicillin, and $100 \mu \mathrm{g} / \mathrm{mL}$ streptomycin. Eosinophils $\left(500 \mu \mathrm{L}, 10^{5} / \mathrm{mL}\right)$ were treated with or without rh-IL-37 (1-100 ng/mL) and eotaxin $(1 \mathrm{ng} / \mathrm{mL})$. ECP protein changes were detected by Unicap system.

2.8. Intranasal Mometasone Furoate Therapy. All AR children underwent a 4-week course of intranasal mometasone furoate (50 $\mu \mathrm{g}$ per puff per nostril to both nostrils, once daily). At the end of treatment, the nose symptoms (runny nose, sneezing, and blocked nose), eye symptoms (streaming and swelling, redness and itching), and lung symptoms (breathlessness, cough, wheeze and chest tightness) were scored by the children as follows: $0=$ no symptoms, $1=$ slight symptoms, 2 = moderate symptoms, and $3=$ severe symptoms. Besides, blood and nasal lavage samples were collected and changes of IL-37b protein expression were detected with ELSIA.

2.9. Statistical Analysis. All data were expressed as mean \pm SD except additional note. Statistical significance between different groups was determined using nonparametric MannWhitney $U$ test. The Spearman rank correlation test was used to analyze the correlation among the expression of biomarkers and clinical stage. $P<0.05$ was considered as significant difference.

\section{Results}

3.1. Demographic and Laboratory Characteristics of the Study Population. This study was conducted with 65 children, 40 of whom suffered from AR, with ages ranging between 16 and 187 months (mean age: $73.2 \pm 33.0$ months, 22 males), and 25 of whom were healthy controls with ages ranging between 15 and 184 months (mean age: $72.0 \pm 31.8$ months, 11 males). The demographic features and laboratory parameters of the population are presented in Table 1. Asthma was found to be $25 \%$ in the AR children. When the two groups were compared, the basophil count, the eosinophil count, total serum IgE, and ECP levels were found to be higher in the AR without asthma group than those of the control group, especially in AR with asthma group.

\subsection{Decreased IL-37b $m R N A$ and Protein Levels in Relation} to Th1/Th2/Treg Cytokines in AR. The serum and local IL37b mRNA and protein expression in AR were significantly lower than those in the normal controls $(P<0.001$, Figures $1(\mathrm{a})-1(\mathrm{~d}))$. However, when we subdivided the AR group into asthma and nonasthma group, we found no difference of IL$37 \mathrm{~b}$ expression levels between two groups. We also compared IL-37 expression between AR children $>6 \mathrm{yr}$ and $<6 \mathrm{yr}$ and 


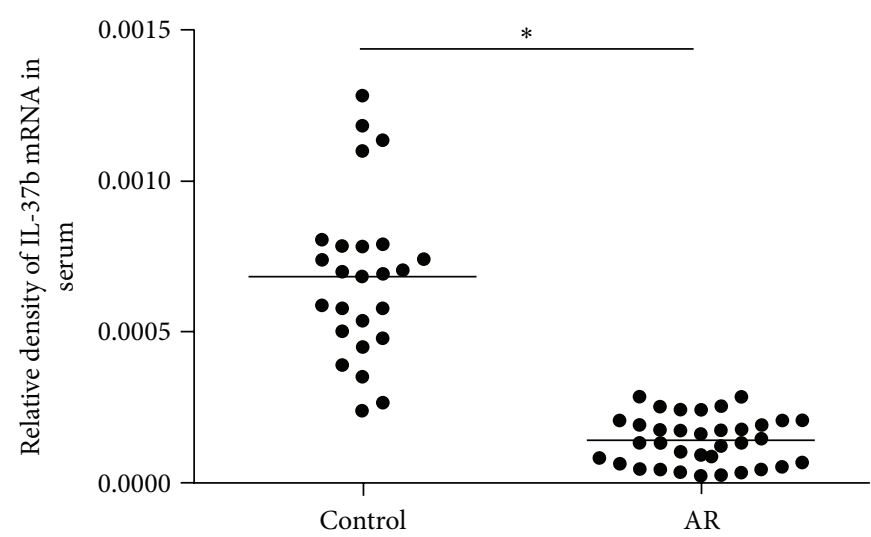

(a)

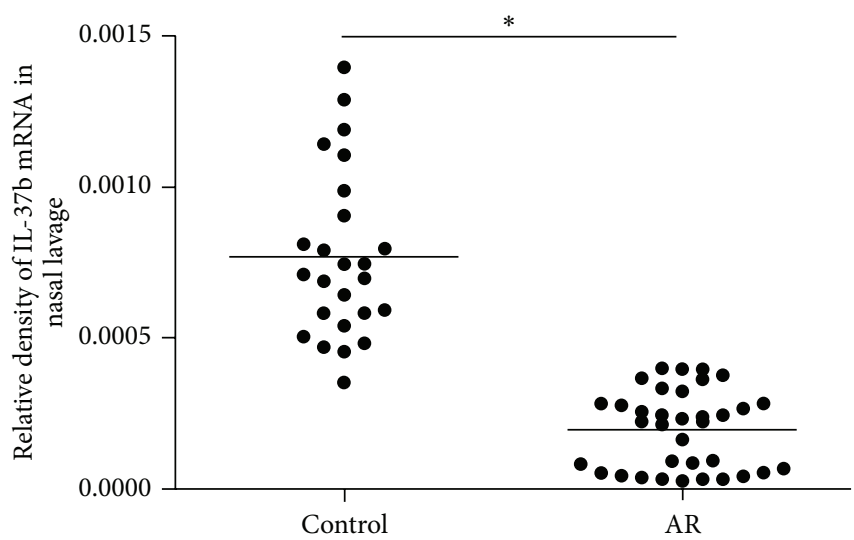

(c)

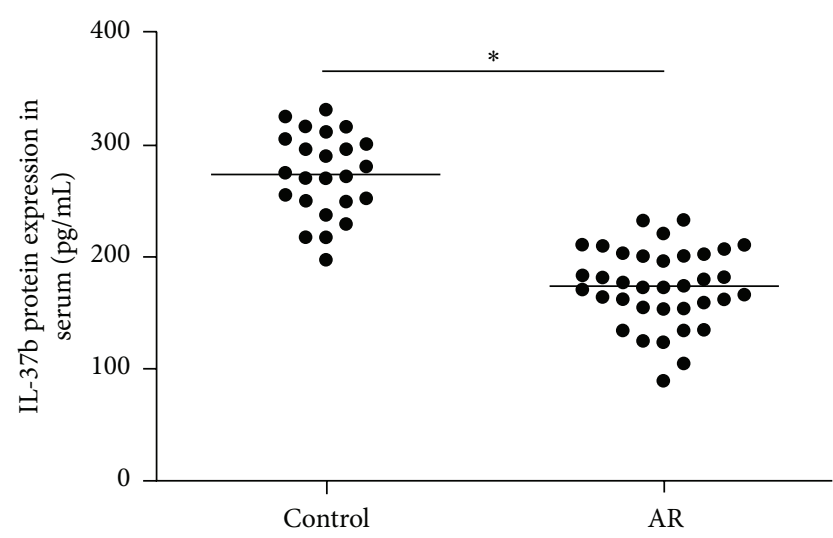

(b)

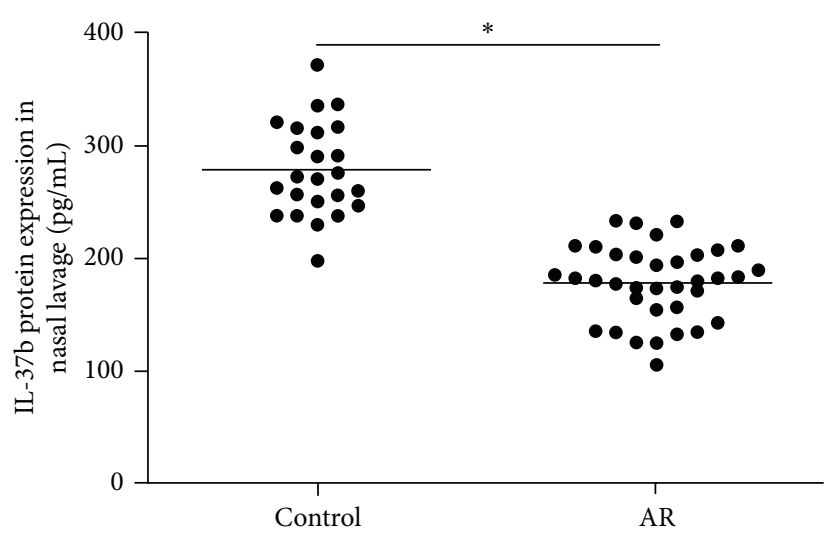

(d)

FIGURE 1: The serum and nasal lavage mRNA and protein expression of IL-37b in AR and normal control. (a) The serum IL-37b mRNA level in AR and normal control; (b) the serum IL-37b protein level in AR and normal control; (c) the nasal lavage IL-37b mRNA level in AR and normal control; (d) the nasal lavage IL-37b protein level in AR and normal control. ${ }^{*} P<0.05$, comparing the two groups.

no differences were found (data not shown). Our results showed enhanced IL-4, IL-13, and IL-5 protein expression, especially in children with asthma and decreased IL-12, IFN$\gamma$, and IL-10 protein expression in serum and nasal lavage of AR children compared with control group $(P<0.001$, Figures 2(a)-2(l)). Nasal IL-4, IL-5, and IL-13 were negatively correlated with local IL-37b $(P<0.05$, Figures 3(a)-3(c)). The serum ECP and IgE levels as well as eosinophil counts were found to be negatively correlated with serum IL-37b expression $(P<0.05$, Figures $3(\mathrm{~g})-3(\mathrm{i}))$. No relationship between IL-37b and IL-12, IFN- $\gamma$, and IL-10 was found (Figures 3(d)-3(f)).

3.3. Decreased IL-37b Expression in AR by IHC. In normal tissues, some epithelial cells, interstitial cells, and glandular cells were positive for IL-37b and IL-37b immunoreactivity was enhanced significantly in controls compared with AR samples (Figures 4(a) and 4(b)). We also detected IL-12 (Figures 4(c) and 4(d)), IL-4 (Figures 4(e) and 4(f)), and IL-1 (Figures 4(g) and 4(h)) and the results showed that the number of IL- 4 and IL-1 positive cells in AR was significantly higher than that of control, while the IL-12 positive cells presented as opposite trend (Table 2).
TABLE 2: Cell count of IL-37b and related cytokines in AR and control tissue (median $\pm \mathrm{IQR})$.

\begin{tabular}{lcc}
\hline Groups & AR group & Control group \\
\hline IL-37b & $4.8 \pm 2.3^{*}$ & $16.4 \pm 4.3$ \\
IL-4 & $12.3 \pm 4.5^{*}$ & $4.5 \pm 1.9$ \\
IL-12 & $11.3 \pm 5.6^{*}$ & $22.1 \pm 7.8$ \\
IL-1 & $25.2 \pm 8.1^{*}$ & $8.1 \pm 2.4$ \\
\hline
\end{tabular}

${ }^{*}$ Compared with control group, $P<0.05$.

3.4. IL-37b Regulated Th2 Cytokines Expression in PBMCs through Mitogen-Activated Protein Kinase (MAPK) and Phosphatidylinositol3-Kinase (PI3K) Pathway. After stimulation with various concentrations of rhIL-37b $(1-100 \mu \mathrm{g})$, we found significant downregulation of Th2 cytokines (IL-4, IL5, and IL-13) in a dose and time dependent manner and this effect was blocked after treatment with SB203580 and LY294002 (Figures 5(a)-5(f)). However, our results showed that IL-37b did not regulate Th1 cytokines and IL-10 expression. To investigate the effect of Th1/Th2/Treg cytokines on IL-37b expression, we used rhIL-4, rhIL-13, rhIL-5, rhIL12 , rhIFN- $\gamma$, and rhIL-10 to stimulate PBMCs for 24 hours 


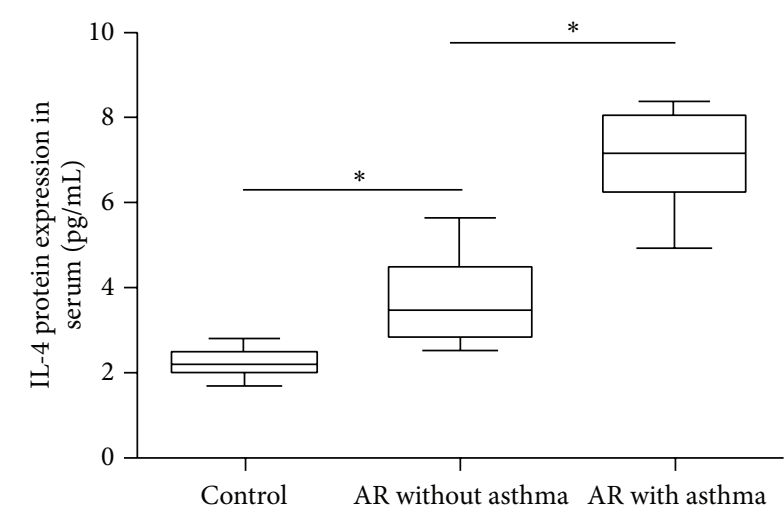

(a)

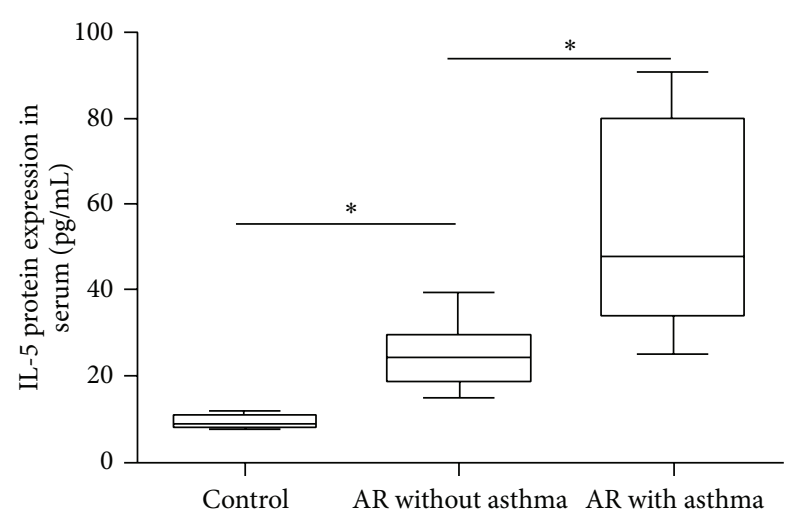

(c)

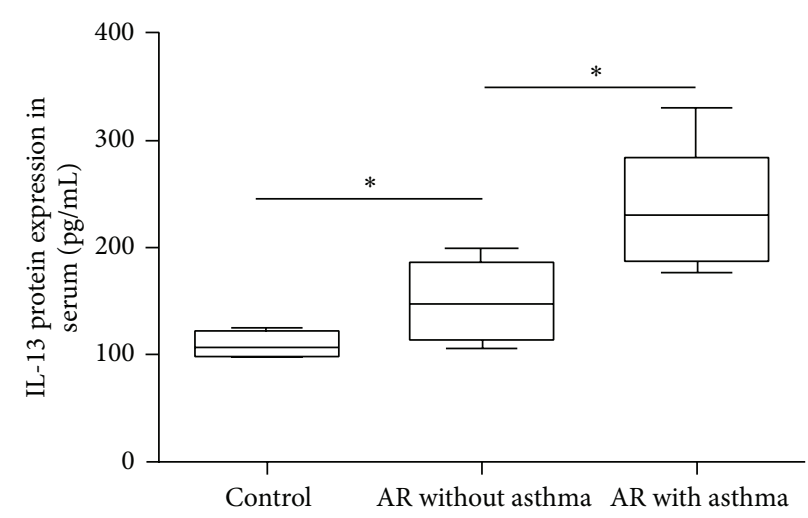

(e)

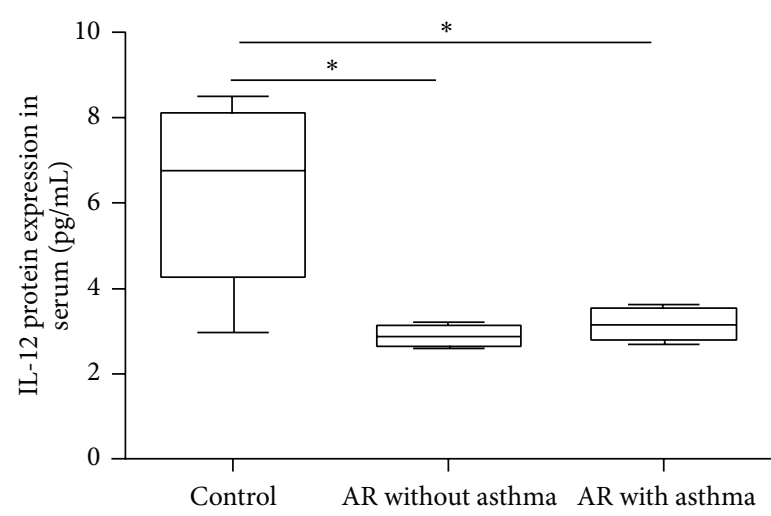

(g)

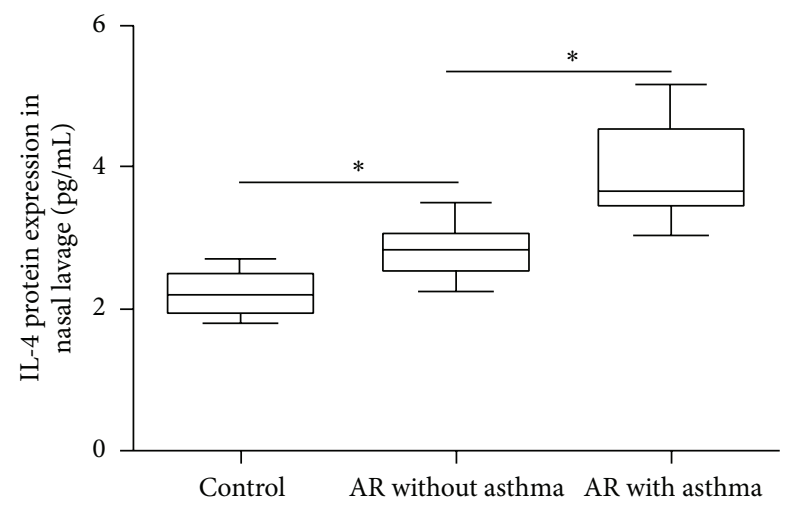

(b)

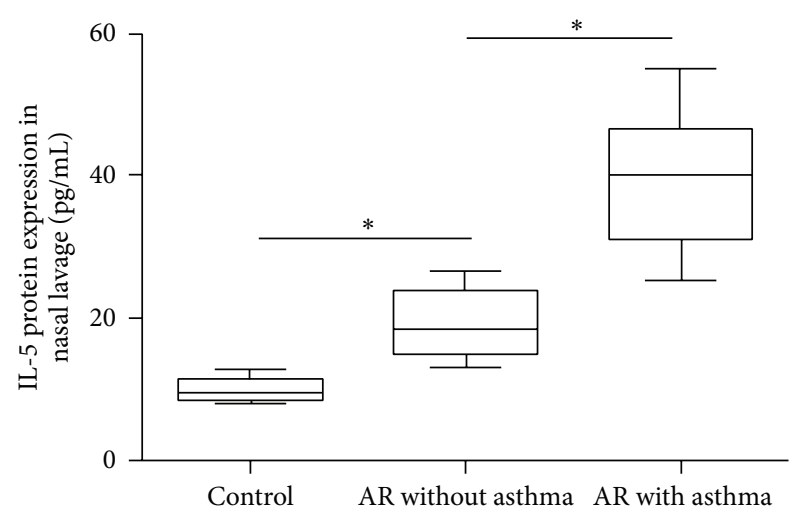

(d)

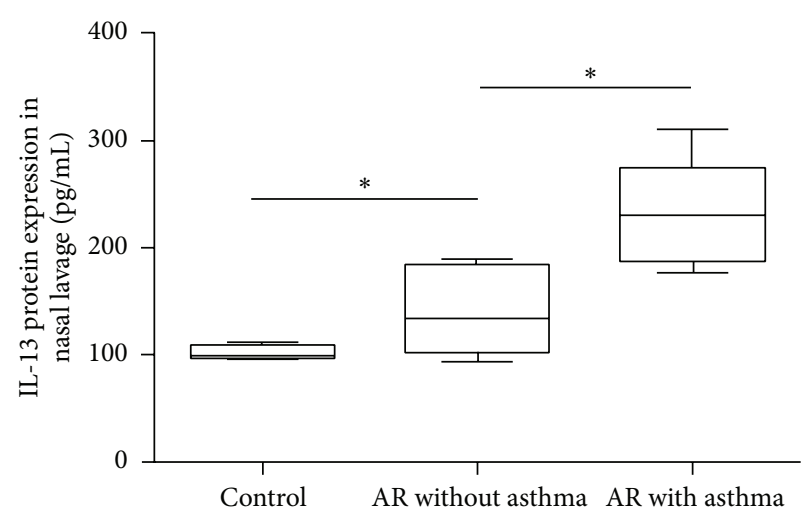

(f)

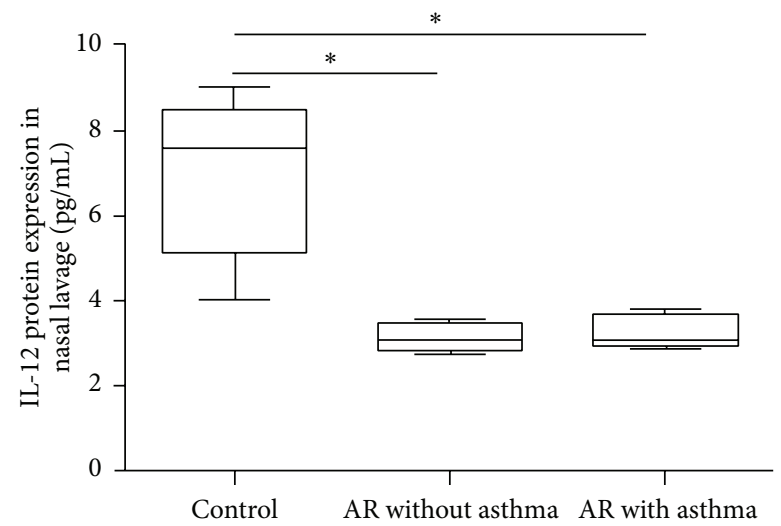

(h)

Figure 2: Continued. 


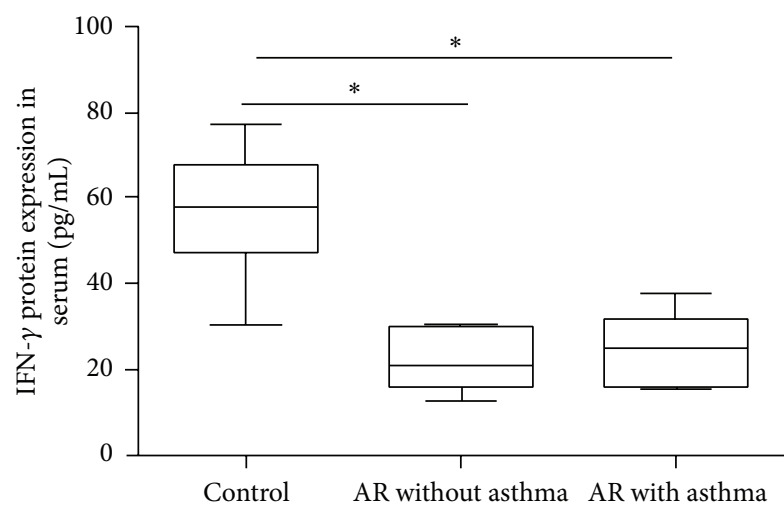

(i)

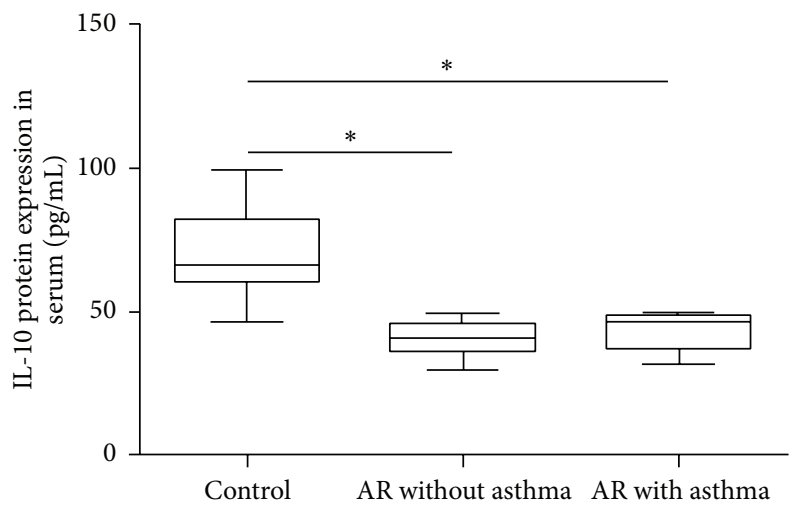

(k)

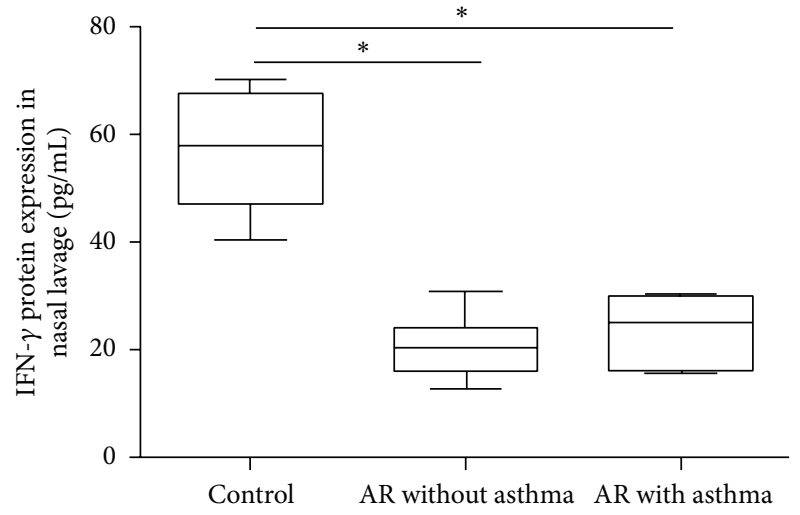

(j)

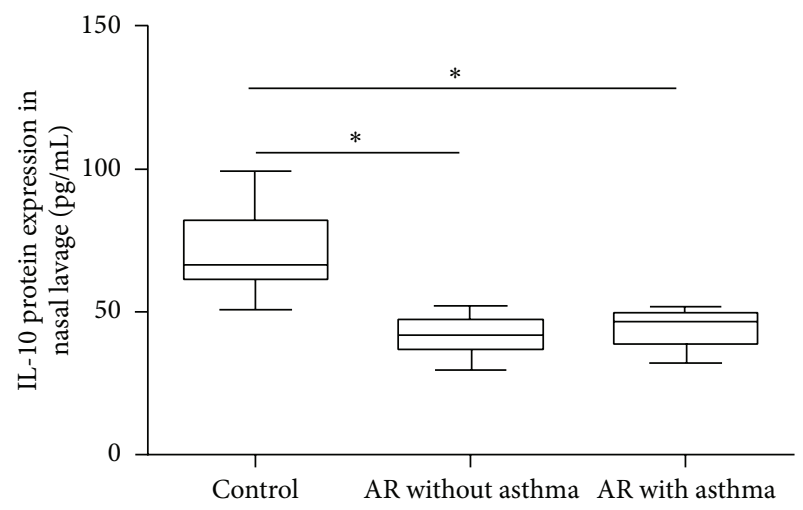

(1)

FIgURE 2: The serum and nasal lavage protein expression of Th2 (IL-4, IL-5, and IL-13), Th1 (IL-12, IFN- $\gamma$ ) and Treg (IL-10) cytokines in AR with asthma, AR without asthma, and control groups. (a)-(f) The serum and nasal lavage protein expression of Th2 (IL-4, IL-5, and IL-13) cytokines in AR with asthma, AR without asthma, and control groups; (g)-(j) the serum and nasal lavage protein expression of Thl (IL-12, IFN- $\gamma$ ) cytokines in AR with asthma, AR without asthma, and control groups; (k), (l) the serum and nasal lavage protein expression of Treg (IL-10) cytokines in AR with asthma, AR without asthma, and control groups. ${ }^{*} P<0.05$, comparing the two groups.

and found that Th2 cytokines (rhIL-4, rhIL-13, and rhIL5) decreased IL-37b expression (Figures 6(a)-6(c)), whereas Th1 cytokines (rhIL-12, rhIFN- $\gamma$ ) had no effect on IL-37b expression (Figures 6(e) and 6(f)). Interestingly, rhIL-10 can upregulate IL-37b expression by PBMCs (Figure 6(d)).

3.5. IL-37b Induces ECP Production by Eosinophils. After stimulation with various concentrations of rhIL-37b (1$100 \mathrm{ng} / \mathrm{mL}$ ), we found significant downregulation of ECP level by eosinophils in a dose and time dependent manner (Figures 7(a) and 7(b)).

3.6. Intranasal Mometasone Furoate Therapy Downregulates Local IL-37b Expression. After 4-week course of intranasal mometasone furoate ( $50 \mu \mathrm{g}$ per puff per nostril to both nostrils, once daily), we found significant relieve of symptoms of AR children (Table 3). Nasal lavage IL-37b protein expression was enhanced significantly after treatment and its expression was negatively related with total symptom scores (Figures $8(\mathrm{a})$ and $8(\mathrm{~b}))$.
TABLE 3: Clinical outcome of 40 AR children after treatment (median \pm IQR).

\begin{tabular}{ccc}
\hline & Before treatment & After treatment \\
\hline Symptom scores & & \\
nose symptom & $2.3 \pm 0.5$ & $0.7 \pm 0.1^{*}$ \\
lung symptom & $1.5 \pm 0.4$ & $1.0 \pm 0.2^{*}$ \\
eye symptom & $1.8 \pm 0.3$ & $0.9 \pm 0.4^{*}$ \\
\hline Total scores & $5.6 \pm 1.2$ & $2.4 \pm 0.5^{*}$ \\
\hline
\end{tabular}

${ }^{*}$ Compared with baseline level, $P<0.05$.

\section{Discussion}

$\mathrm{AR}$ is a common disease in children which is characterized by persistent inflammation of the nasal mucosa, typically showing a Th2 skewed eosinophilic inflammation with high levels of IL-5 and IgE. Th2 cytokines play an important role in the development and deterioration of AR. At present, intranasal steroid is the first-line treatment for $A R$ and its mechanism includes regulation of Th1/Th2 balance and inhibition of inflammatory cytokines. 


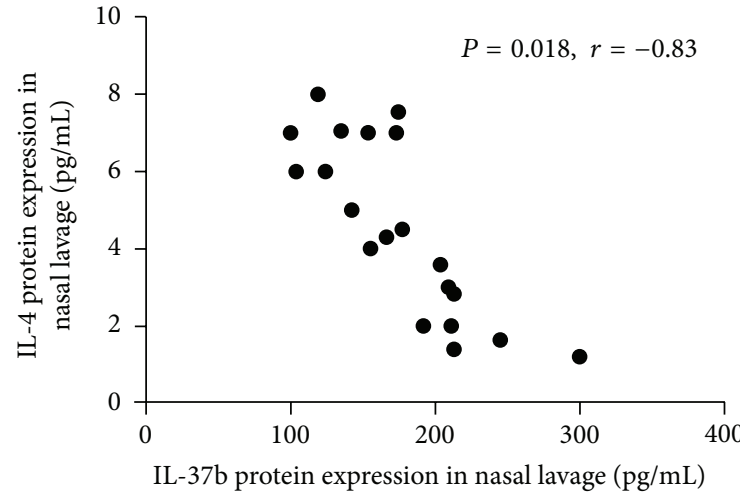

(a)

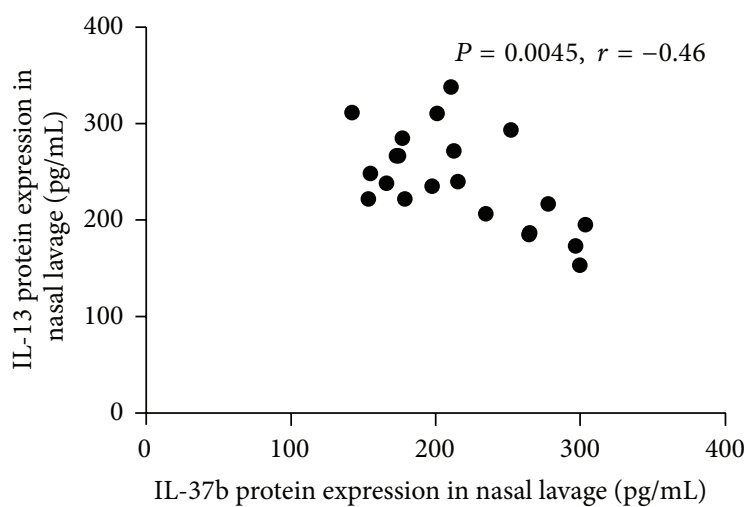

(c)

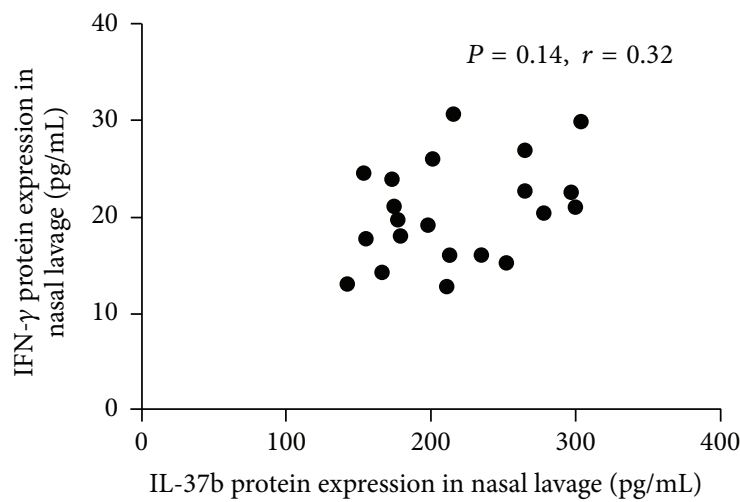

(e)

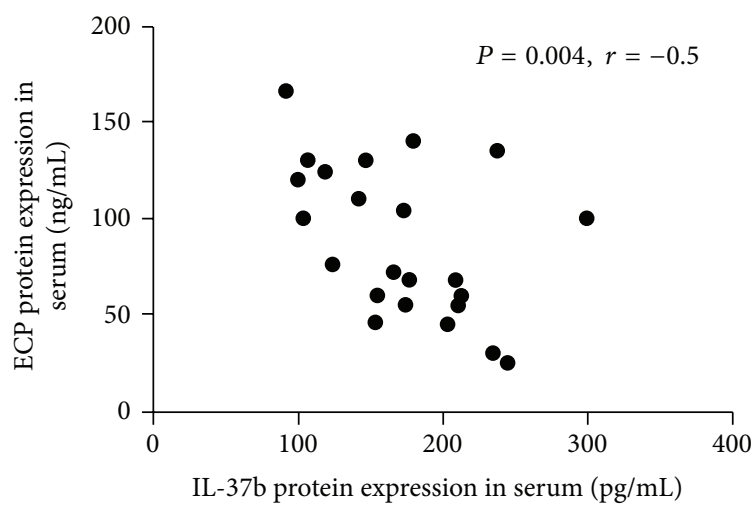

(g)

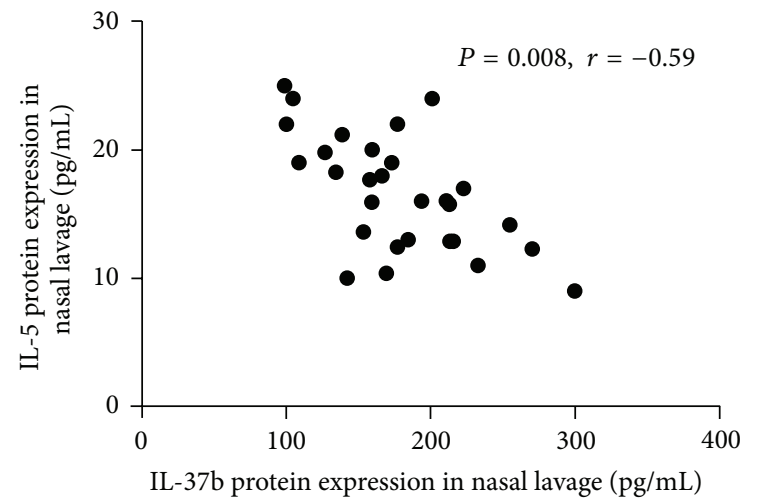

(b)

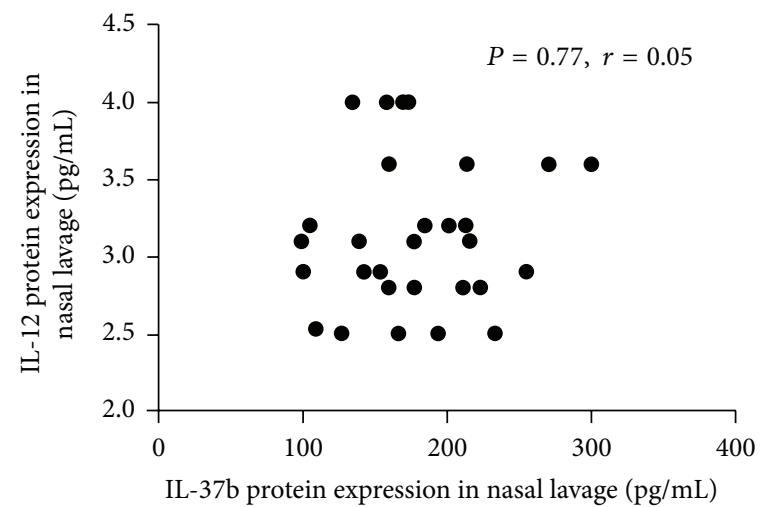

(d)

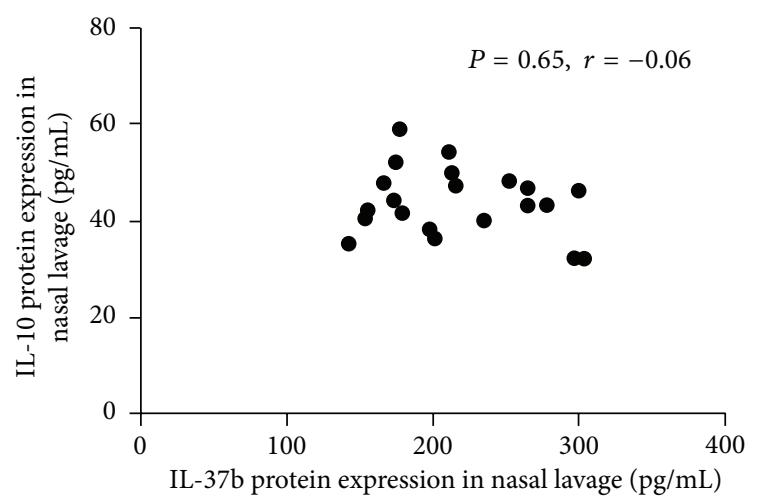

(f)

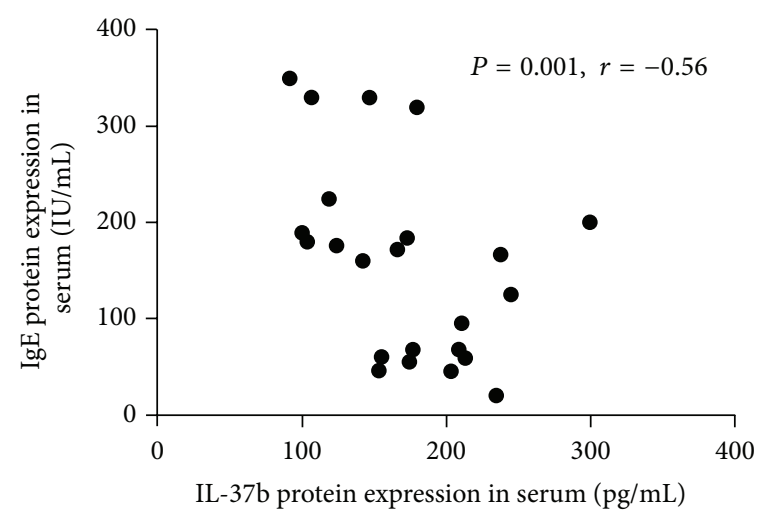

(h)

Figure 3: Continued. 


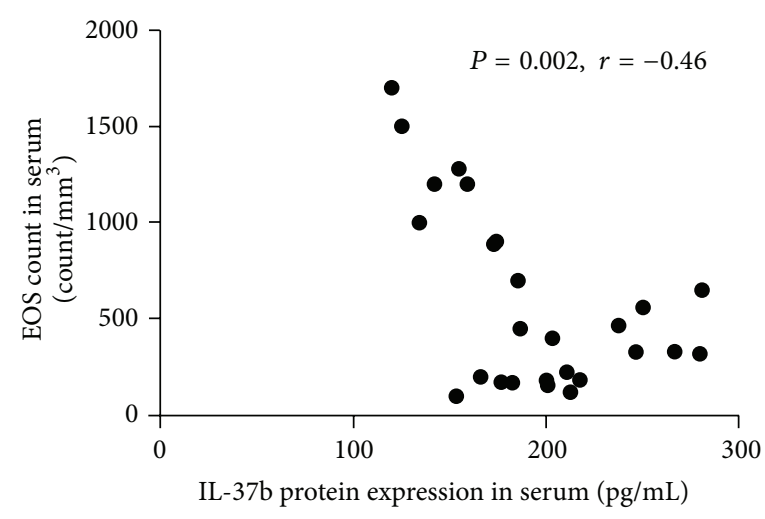

(i)

FIgURE 3: Correlation between IL-37b protein expression and related cytokines or protein. (a) Correlation between nasal IL-37b and IL4 protein; (b) correlation between nasal IL-37b and IL-5 protein; (c) correlation between nasal IL-37b and IL-13 protein; (d) correlation between nasal IL-37b and IL-12 protein; (e) correlation between nasal IL-37b and IFN- $\gamma$ protein; (f) correlation between nasal IL-37b and IL-10 protein; (g) correlation between serum IL-37b and ECP protein; (h) correlation between serum IL-37b and IgE protein; (i) correlation between serum IL-37b and EOS count.

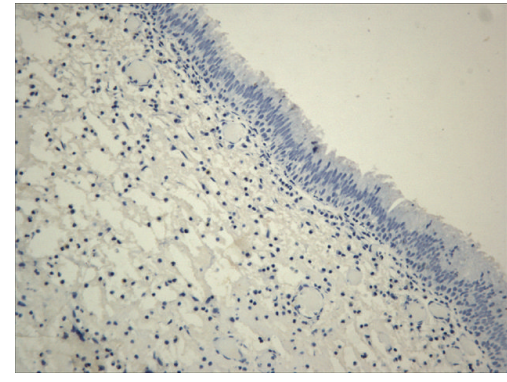

(a)

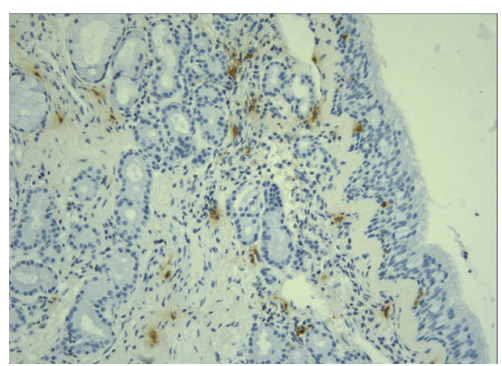

(d)

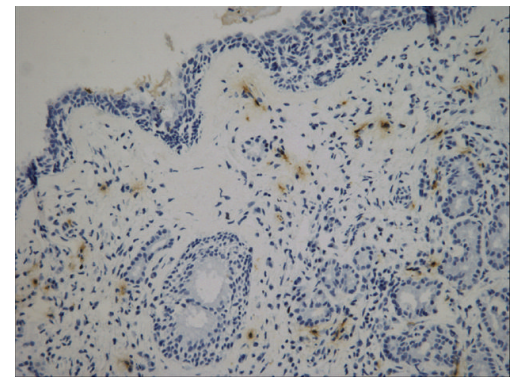

(g)

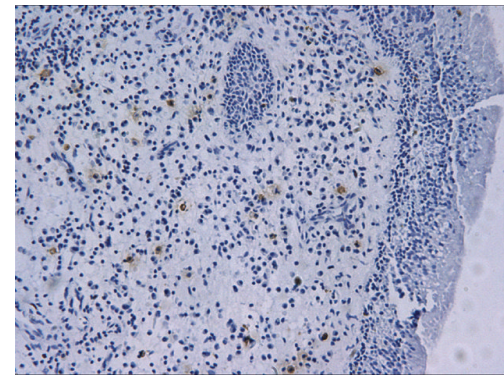

(b)

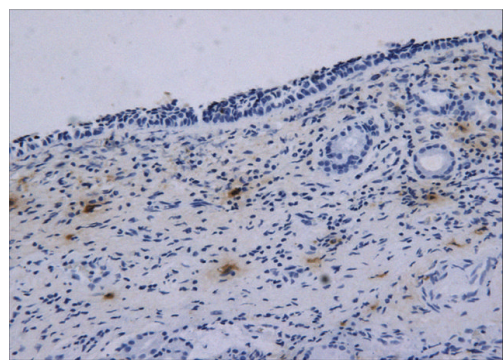

(e)

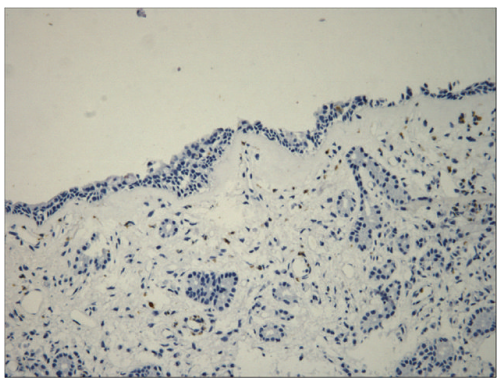

(h)

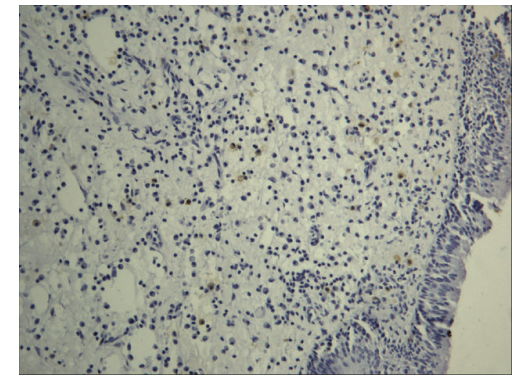

(c)

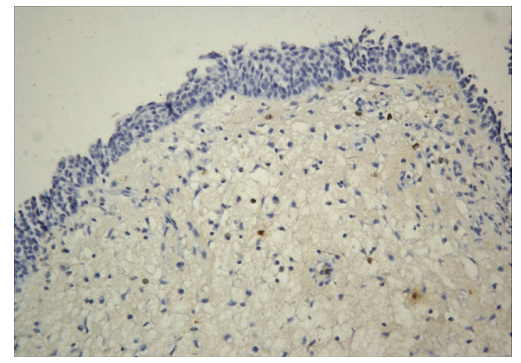

(f)

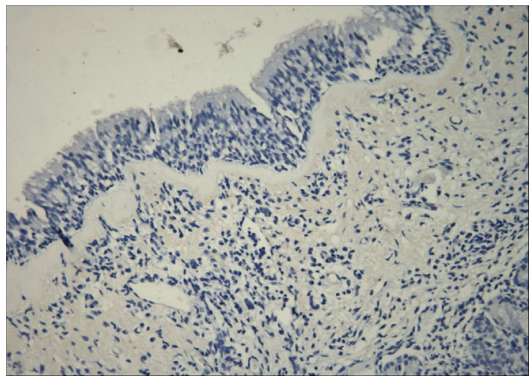

(i)

FIGURE 4: The expression of IL-37b and related cytokines in inferior turbinate of AR children and normal control. (a) IL-37b staining in AR; (b) IL-37b staining in control; (c) IL-12 staining in AR; (d) IL-12 staining in control; (e) IL-4 staining in AR; (f) IL-4 staining in control; (g) IL-1 staining in AR; (h) IL-1 staining in control; (i) IgG control antibody staining. Magnification $\times 200$. 


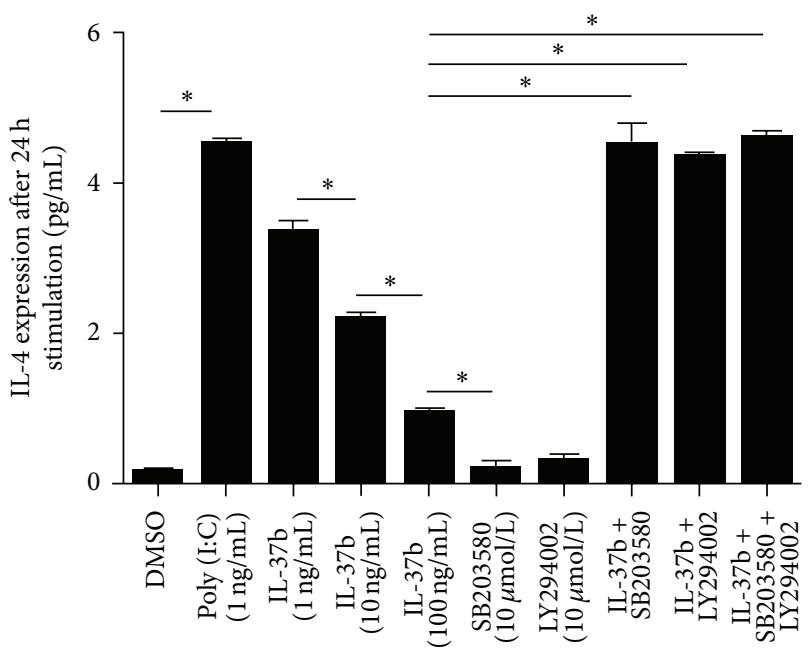

(a)

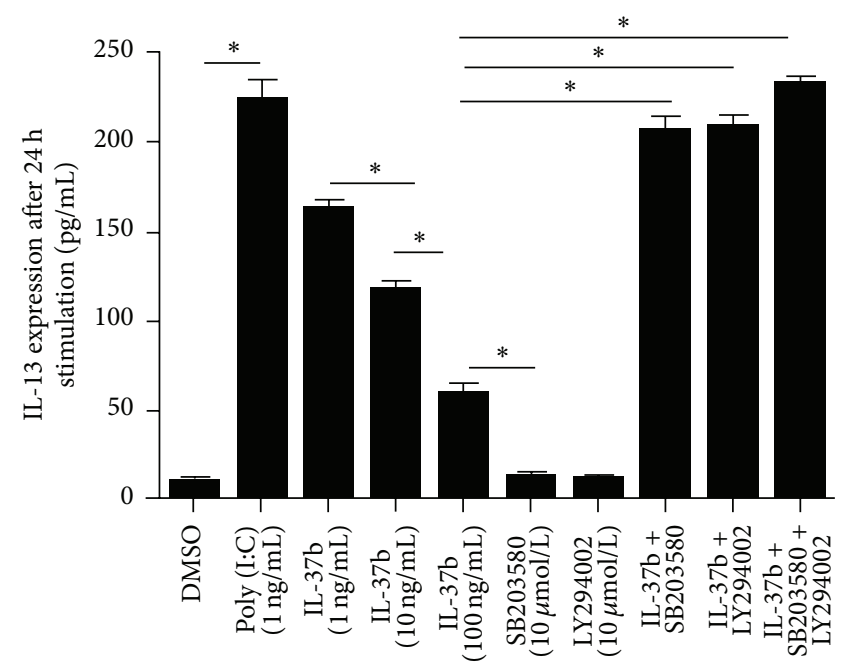

(c)

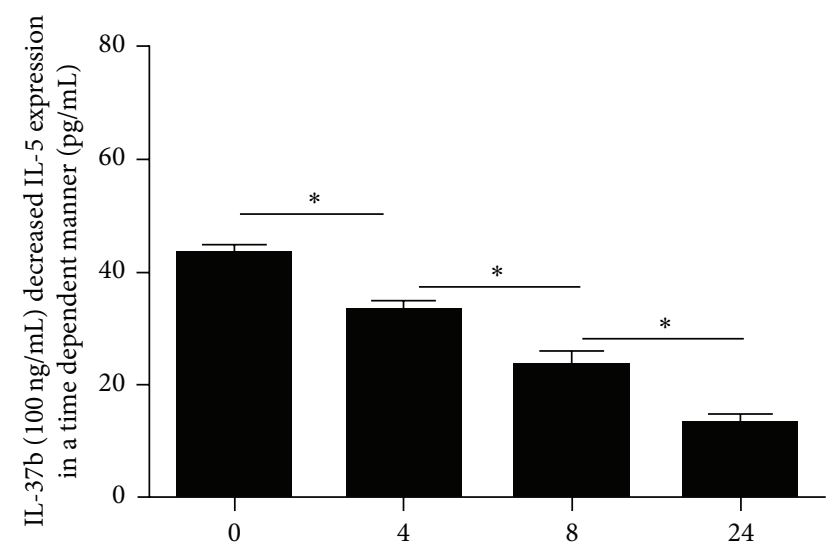

(h)

(e)

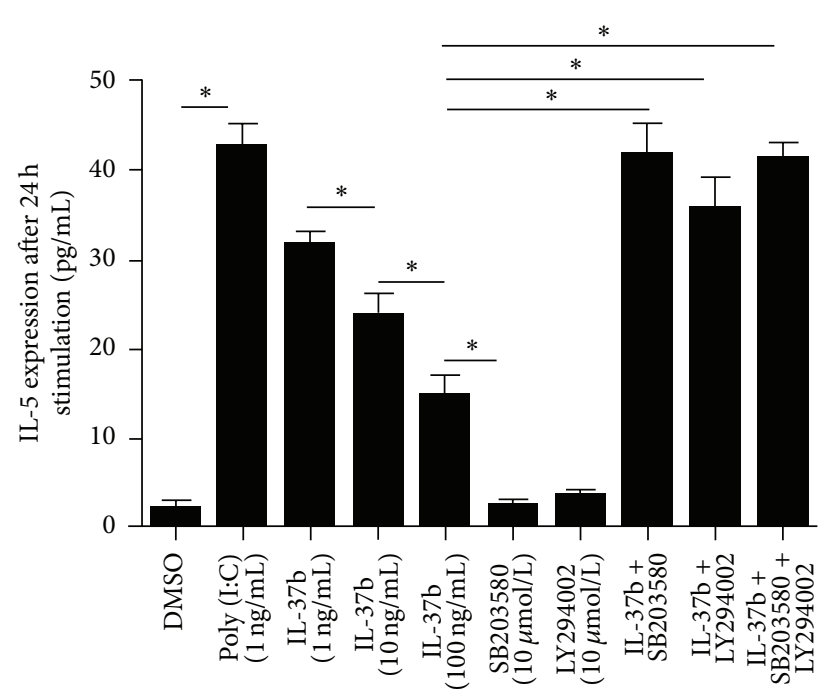

(b)

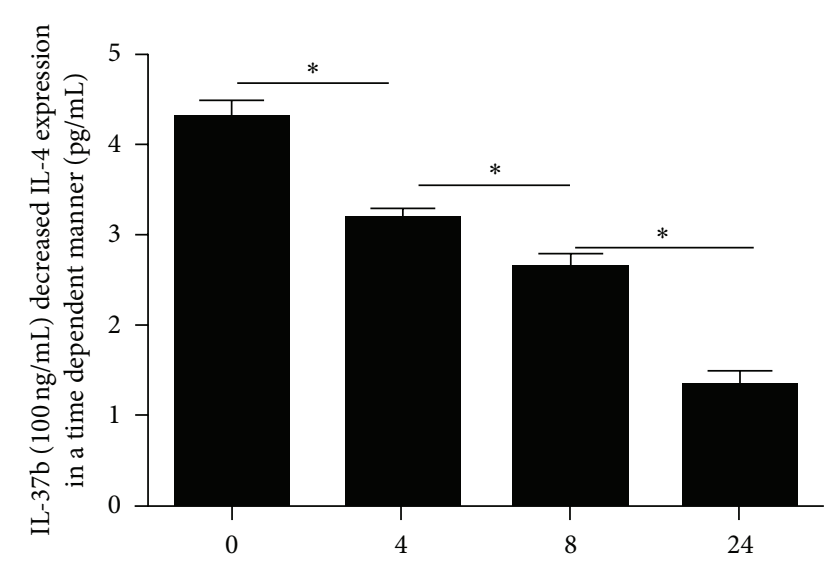

(h)

(d)

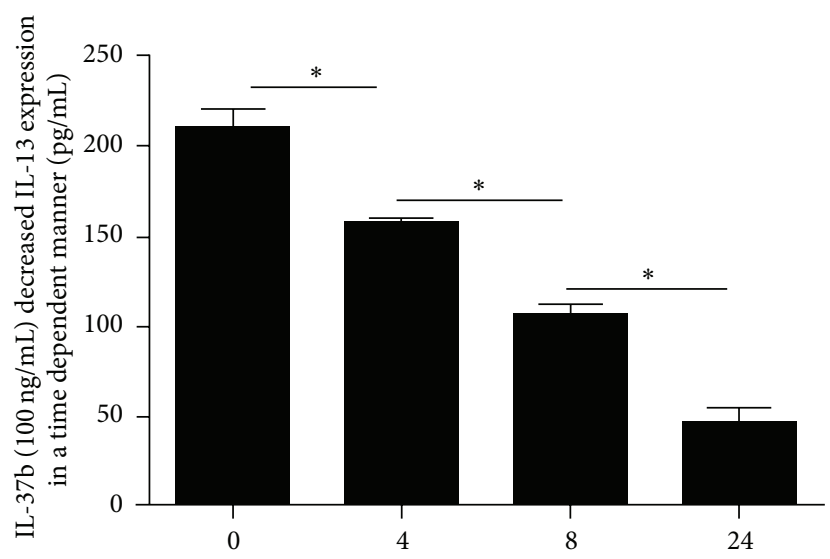

(h)

(f)

FIGURE 5: The regulation of Th2 cytokines (IL-4, IL-5, and IL-13) by IL-37b in PBMC in a dose and time dependent manner. (a) IL-4 expression by PBMC after stimulated with different concentration of IL-37b with or without SB203580 and LY294002; (b) IL-5 expression by PBMC after stimulated with different concentration of IL-37b with or without SB203580 and LY294002; (c) IL-13 expression by PBMC after stimulated with different concentration of IL-37b with or without SB203580 and LY294002; (d) IL-37b decreased IL-4 expression by PBMC in a time dependent manner; (e) IL-37b decreased IL-5 expression by PBMC in a time dependent manner; (f) IL-37b decreased IL-13 expression by PBMC in a time dependent manner. ${ }^{*} P<0.05$, comparing the two groups. 


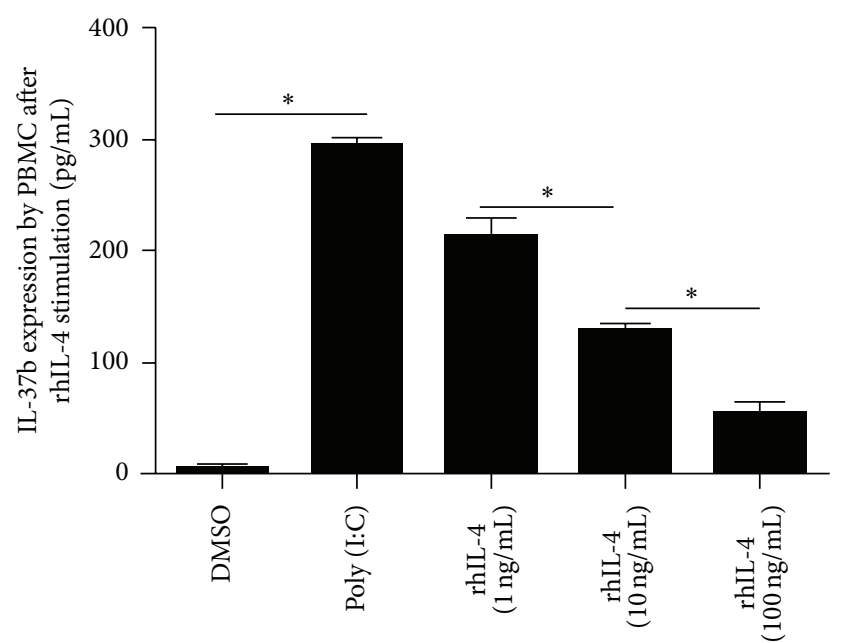

(a)

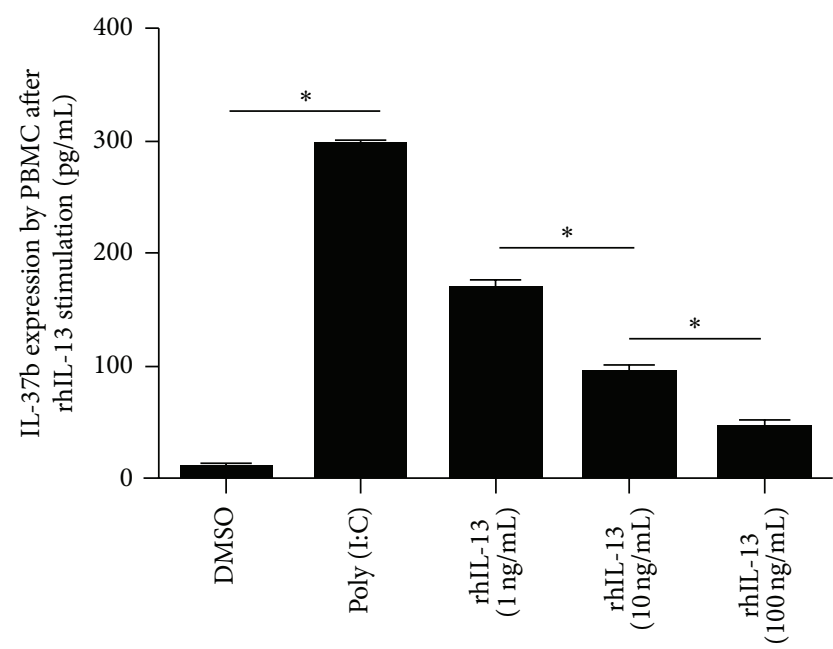

(c)

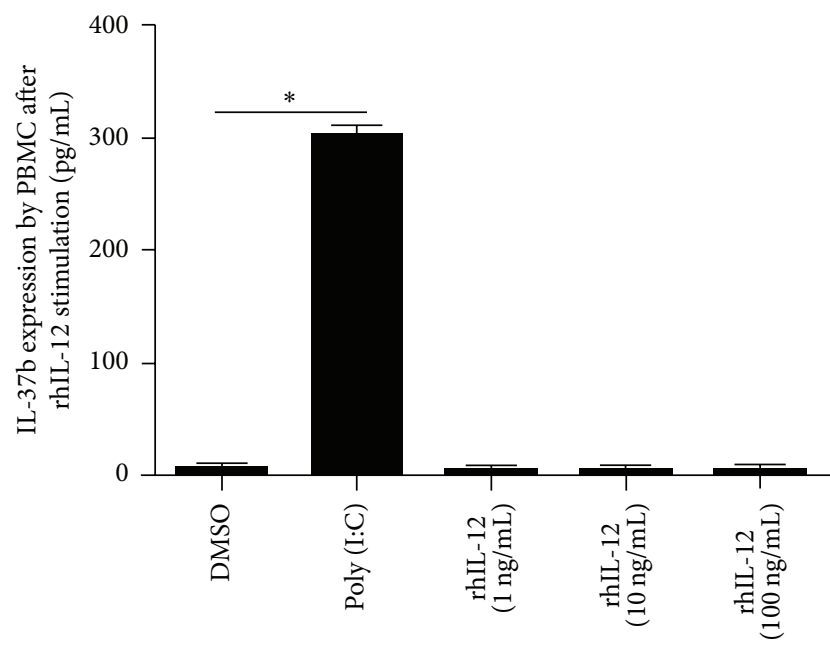

(e)

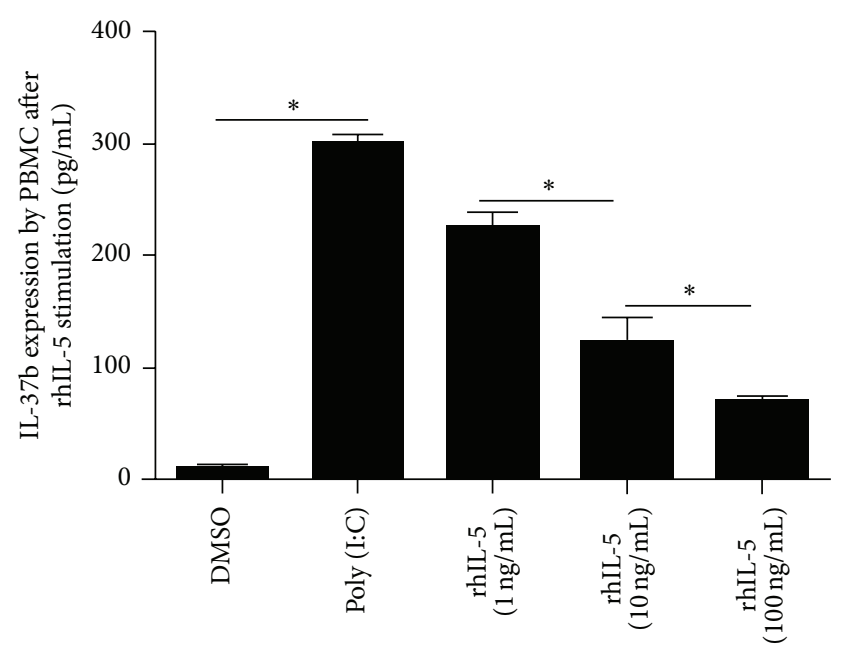

(b)

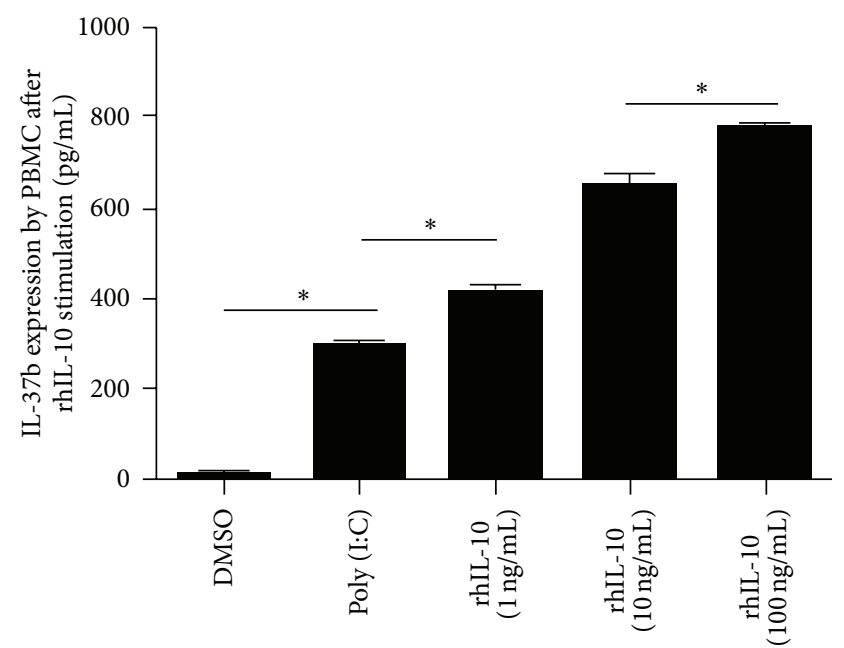

(d)

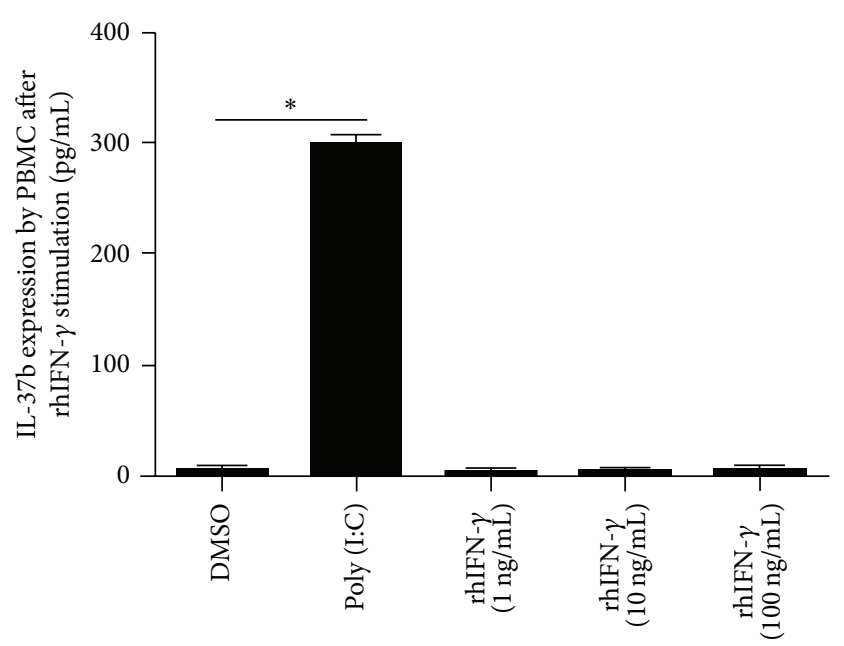

(f)

Figure 6: Regulation of IL-37b expression by Th2 cytokines (rhIL-4, rhIL-5, rhIL-13), Th1 cytokines (rhIL-12, rhIFN- $\gamma$ ), and Treg cytokine (rhIL-10) in PBMC. (a) IL-37b expression in a dose dependent manner by PBMC after $24 \mathrm{~h}$ stimulation with rhIL-4; (b) IL-37b expression in a dose dependent manner by PBMC after $24 \mathrm{~h}$ stimulation with rhIL-5; (c) IL-37b expression in a dose dependent manner by PBMC after $24 \mathrm{~h}$ stimulation with rhIL-13; (d) IL-37b expression in a dose dependent manner by PBMC after $24 \mathrm{~h}$ stimulation with rhIL-10; (e) IL-37b expression was not affected after $24 \mathrm{~h}$ stimulation with rhIL-12; (f) IL-37b expression was not affected after $24 \mathrm{~h}$ stimulation with rhIFN- $\gamma$. ${ }^{*} P<0.05$, comparing the two groups. 


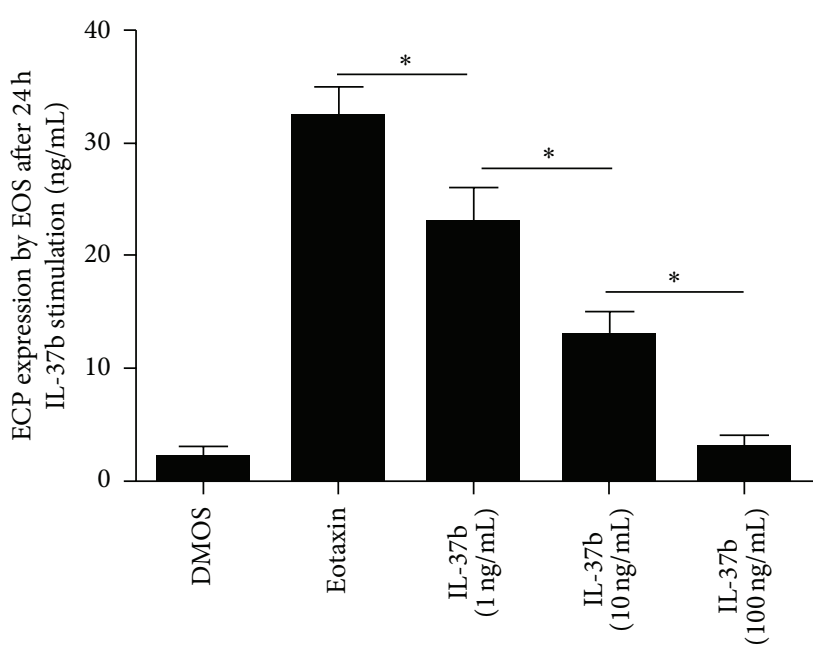

(a)

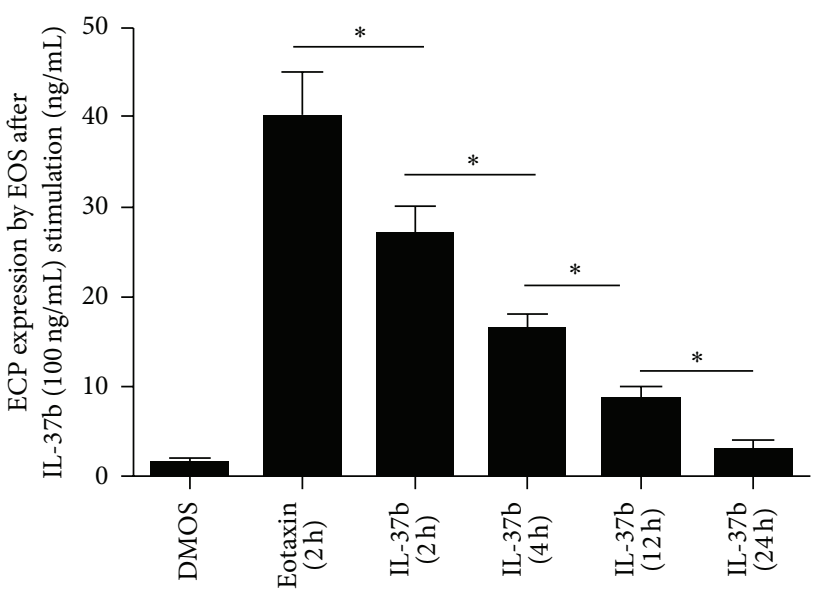

(b)

FIGURE 7: Regulation of ECP expression by EOS after stimulation with IL-37b. (a) ECP expression in a dose dependent manner by EOS after stimulation with rhIL-37b; (b) ECP expression in a time dependent manner by EOS after stimulation with rhIL-37b. ${ }^{*} P<0.05$, comparing the two groups.

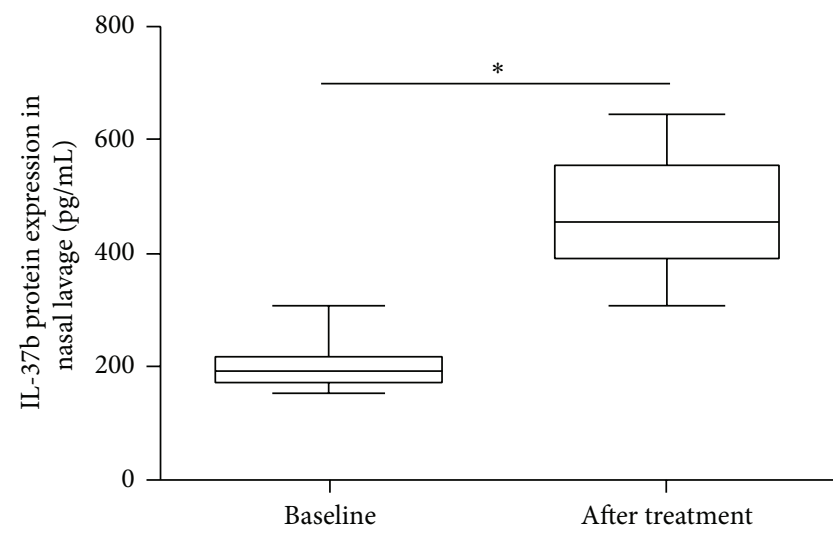

(a)

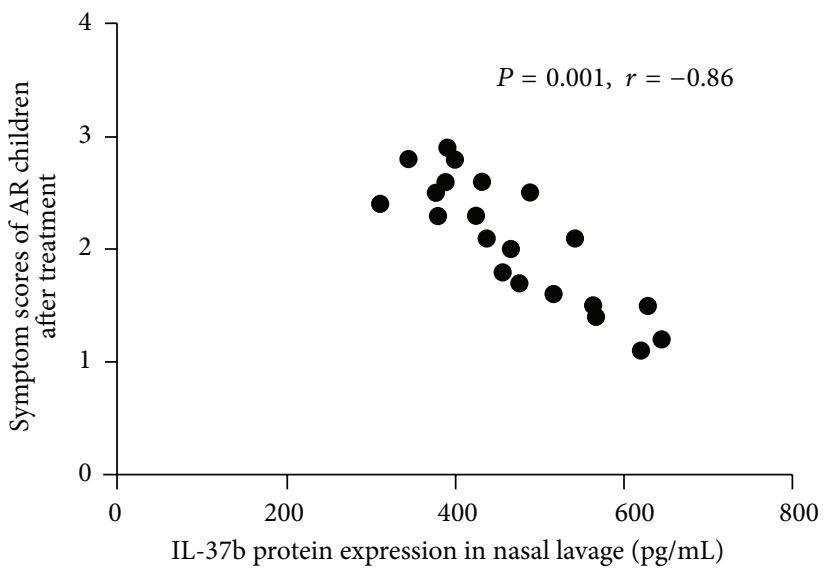

(b)

FIGURE 8: Nasal lavage IL-37b protein expression after treatment and its correlation with total symptom scores. (a) Nasal lavage IL-37b protein expression before and after treatment. (b) Correlation between nasal lavage IL-37b protein expression and total symptom scores after treatment. ${ }^{*} P<0.05$, comparing the two groups.

At present, most studies on pathogenesis of AR concentrated on the production of inflammatory cytokines instead of anti-inflammatory cytokines. IL-37 (IL-1F7) is a newly reported molecular of IL-1 family with anti-inflammatory effect [18]. IL-37 expression was found in many cancer cells such as stroma of colon carcinomas, and ductal mammary carcinoma and also in blood monocytes, fully differentiated keratinocytes in stratum granulosum of skin, PBMC, and dendritic cell $[19,20]$. IL-37b has potent anti-inflammatory properties and many studies have elucidated its precise role in autoimmune disease such as systemic lupus erythematosus (SLE), rheumatoid arthritis (RA), inflammatory bowel disease (IBD), guillain-Barré syndrome, and atopic dermatitis
(AP) $[21,22]$. However, its role in respiratory disease was not reported.

As IL-37b was believed to be the most important isoform of IL-37, thus our study focuses on it and we provide the first evidence that IL-37b expression was negatively related to enhanced Th2 inflammation in AR. In normal nasal mucosa, we found that IL-37b was expressed by epithelial, interstitial cells, and glandular cells. However, IL-37b expression in AR was relatively weak. Interestingly, we found that IL$37 \mathrm{~b}$ expression was not affected by the state of asthma and age in children. Consistent with our results, Fujita et al. [22] detected IL-37b expression in AP and their results showed that most AP patients presented as high IL-37 level, 
but several severe AD showed low level of IL-37. These results suggested that IL-37 played different roles in different disease states and IL-37 isoforms may represent even different functions. Besides, when MAPK and PI3K pathway inhibitor were added to PBMCs, the inhibitory effect on Th2 cytokines by IL-37b was significantly decreased, suggesting that MAPK and PI3K pathways were involved in IL-37b mediated Th2 inflammation regulation, which was consistent with previous report [23].

In Imaeda's study [23], IL-37b was found to inhibit CXCL10, a Th1-chemokine, suggesting its potential role in inhibiting Thl inflammation. On the contrary, our data showed that Thl cytokines were not correlated with IL-37b. We also found that IL-37b did not affect IL-10 expression. These results suggested that IL-37 regulation of Th2 cytokines is not IL-10 dependent, which is inconsistent with Mcnamee's study [11], who reported that IL-37 isoforms not only suppress Th2 cytokines, but also induce IL-10. However, our data showed that rhIL-10 can upregulate IL-37b expression by PBMCs and its mechanism needs further exploration.

Eosinophils mediate epithelial damage via the release of preformed effector molecules, such as major basic protein and ECP. Eosinophils play a critical role in the maintenance and progression of AR by promoting airway dysfunction and tissue remodeling. Our results show serum ECP and IgE levels and eosinophil counts were negatively correlated with serum IL-37b. Thus, we purified eosinophils and found that IL-37b can inhibit ECP expression by eosinophils directly in a dose and time dependent manner. Our results provide a new eosinophil regulator in the development of AR.

Finally, we analyzed the IL-37b expression after intranasal steroid treatment. We found the treatment decreased nasal IL-37b expression and disease symptoms, suggesting that intranasal steroid may improve symptoms through regulation of IL-37b expression. However, inconsistent with our results, Song's study [24] showed that glucocorticoid can downregulate the expression of IL-37b and other cytokines in SLE patients. These differences in expression of IL-37b in above-mentioned diseases suggested that IL-37b played various roles in different backgrounds.

\section{Conclusions}

In summary, we have shown the expression, distribution, and regulation of IL-37b in AR children and demonstrated the importance of decreased IL-37b level in regulation of Th1/Th2/Treg balance and activation of eosinophils. Our findings may be beneficial for designing a potential strategy for the optimal prevention and management of AR children.

\section{Conflict of Interests}

The authors declare that they have no financial disclosures or conflict of interests.

\section{Authors' Contribution}

Wenlong Liu and Li Deng contributed equally to this work.

\section{Acknowledgment}

This study was supported by Grants from National Clinical Key Specialty Project Foundation.

\section{References}

[1] D. Strachan, B. Sibbald, S. Weiland et al., "Worldwide variations in prevalence of symptoms of allergic rhinoconjunctivitis in children: the International Study of Asthma and Allergies in Childhood (ISAAC)," Pediatric Allergy and Immunology, vol. 8, no. 4, pp. 161-176, 1997.

[2] B. Björkstén, T. Clayton, P. Ellwoodet et al., "Worldwide time trends for symptoms of rhinitis and conjunctivitis: phase III of the International Study of Asthma and Allergies in Childhood," Pediatric Allergy and Immunology, vol. 19, no. 2, pp. 110-124, 2008.

[3] S. Hamouda, C. Karila, T. Connault, P. Scheinmann, and J. de Blic, "Allergic rhinitis in children with asthma: a questionnairebased study," Clinical and Experimental Allergy, vol. 38, no. 5, pp. 761-766, 2008.

[4] B. S. Bochner and R. P. Schleimer, "Mast cells, basophils, and eosinophils: distinct but overlapping pathways for recruitment," Immunological Reviews, vol. 179, pp. 5-15, 2001.

[5] I. Hansen, L. Klimek, R. Mösges, and K. Hörmann, "Mediators of inflammation in the early and late phase of allergic rhinitis," Current Opinion in Allergy and Clinical Immunology, vol. 4, no. 3, pp. 159-163, 2004.

[6] E. M. Ling, T. Smith, X. D. Nguyen et al., "Relation of $\mathrm{CD} 4+\mathrm{CD} 25+$ regulatory $\mathrm{T}$-cell suppression of allergen-driven T-cell activation to atopic status and expression of allergic disease," The Lancet, vol. 363, no. 9409, pp. 608-615, 2004.

[7] D. Boraschi, D. Lucchesi, S. Hainzlet et al., "IL-37: a new antiinflammatory cytokine of the IL-1 family," European Cytokine Network, vol. 22, no. 3, pp. 127-147, 2011.

[8] P. Bufler, T. Azam, F. Gamboni-Robertsonet et al., "A complex of the IL-1 homologue IL-1F7beta and IL-18-binding protein reduces IL-18 activity," Proceedings of the National Academy of Sciences of the United States of America, vol. 99, no. 21, pp. 1372313728, 2002.

[9] M. F. Nold, C. A. Nold-Petry, J. A. Zepp, B. E. Palmer, P. Bufler, and C. A. Dinarello, "IL-37 is a fundamental inhibitor of innate immunity," Nature Immunology, vol. 11, no. 11, pp. 1014-1022, 2010.

[10] S. Sharma, N. Kulk, M. F. Nold et al., "The IL-1 family member $7 \mathrm{~b}$ translocates to the nucleus and down-regulates proinflammatory cytokines," Journal of Immunology, vol. 180, no. 8, pp. 5477-5482, 2008.

[11] E. N. McNamee, J. C. Masterson, P. Jedlicka et al., "Interleukin 37 expression protects mice from colitis," Proceedings of the National Academy of Sciences of the United States of America, vol. 108, no. 40, pp. 16711-16716, 2011.

[12] J. L. Broek, J. Bousquet, C. E. Baena-Cagnani et al., "Allergic Rhinitis and its Impact on Asthma (ARIA) guidelines: 2010 revision," Journal of Allergy and Clinical Immunology, vol. 126, no. 3, pp. 466-476, 2010.

[13] S. E. Pedersen, S. S. Hurd, R. F. Lemanske Jr. et al., "Global strategy for the diagnosis and management of asthma in children 5 years and younger," Pediatric Pulmonology, vol. 46, no. 1, pp. 1-17, 2011.

[14] K. Irander, J. P. Palm, M. P. Borres, and B. Ghafouri, "Clara cell protein in nasal lavage fluid and nasal nitric oxide-biomarkers 
with anti-inflammatory properties in allergic rhinitis," Clinical and Molecular Allergy, vol. 10, article 4, 2012.

[15] M. M. Bradford, "A rapid and sensitive method for the quantitation of microgram quantities of protein utilizing the principle of protein dye binding," Analytical Biochemistry, vol. 72, no. 1-2, pp. 248-254, 1976.

[16] W. Wen, W. Liu, L. Zhang et al., "Increased neutrophilia in nasal polyps reduces the response to oral corticosteroid therapy," Journal of Allergy and Clinical Immunology, vol. 129, no. 6, pp. 1522-1528, 2012.

[17] I. Puxeddu, A. Alian, A. M. Piliponsky, D. Ribatti, A. Panet, and F. Levi-Schaffer, "Human peripheral blood eosinophils induce angiogenesis," International Journal of Biochemistry and Cell Biology, vol. 37, no. 3, pp. 628-636, 2005.

[18] S. Kumar, P. C. McDonnell, R. Lehr et al., "Identification and initial characterization of four novel members of the interleukin-1 family," Journal of Biological Chemistry, vol. 275, no. 14, pp. 10308-10314, 2000.

[19] S. J. Busfield, C. A. Comrack, G. Yu et al., "Identification and gene organization of three novel members of the IL-1 family on human chromosome 2," Genomics, vol. 66, no. 2, pp. 213-216, 2000.

[20] G. Pan, P. Risser, W. Mao et al., "IL-1H, an interleukin 1-related protein that binds IL-18 receptor/IL-1Rrp," Cytokine, vol. 13, no. 1, pp. 1-7, 2001.

[21] C. Li, P. Zhao, X. Sun, Y. Che, and Y. Jiang, "Elevated levels of cerebrospinal fluid and plasma interleukin-37 in patients with Guillain-Barré syndrome," Mediators of Inflammation, vol. 2013, Article ID 639712, 9 pages, 2013.

[22] H. Fujita, Y. Inoue, K. Seto, N. Komitsu, and M. Aihara, "Interleukin-37 is elevated in subjects with atopic dermatitis," Journal of Dermatological Science, vol. 69, no. 2, pp. 173-175, 2013.

[23] H. Imaeda, K. Takahashi, T. Fujimoto et al., "Epithelial expression of interleukin-37b in inflammatory bowel disease," Clinical and Experimental Immunology, vol. 172, no. 3, pp. 410-416, 2013.

[24] L. Song, F. Qiu, Y. Fan et al., "Glucocorticoid regulates interleukin-37 in systemic lupus erythematosus," Journal of Clinical Immunology, vol. 33, no. 1, pp. 111-117, 2013. 


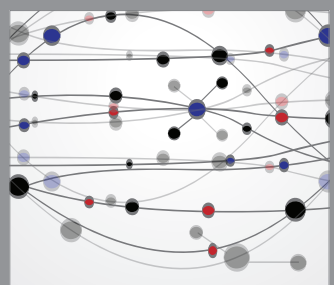

The Scientific World Journal
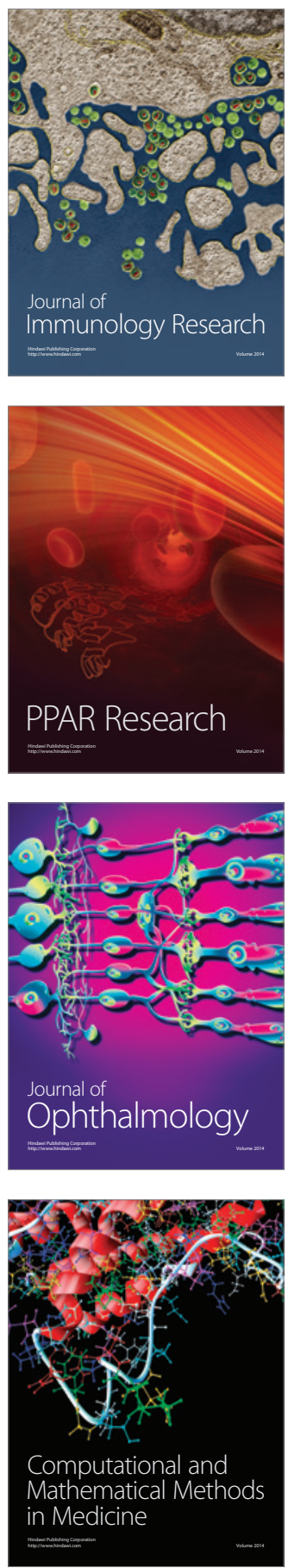

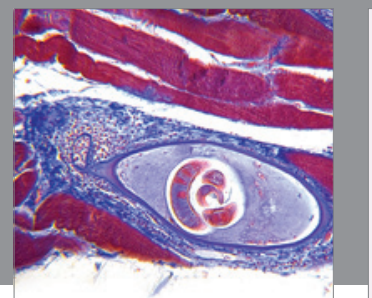

Gastroenterology

Research and Practice
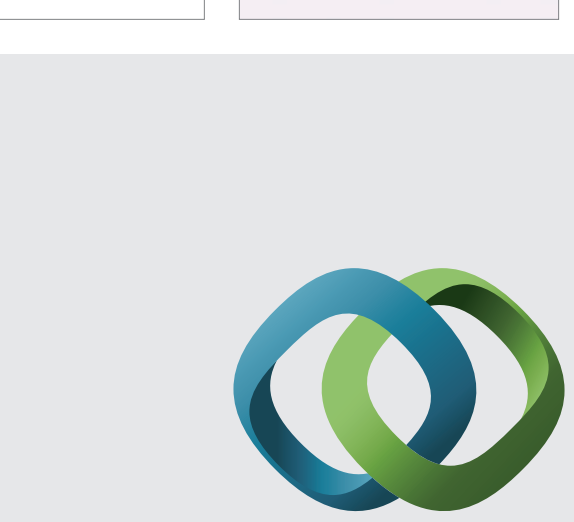

\section{Hindawi}

Submit your manuscripts at

http://www.hindawi.com
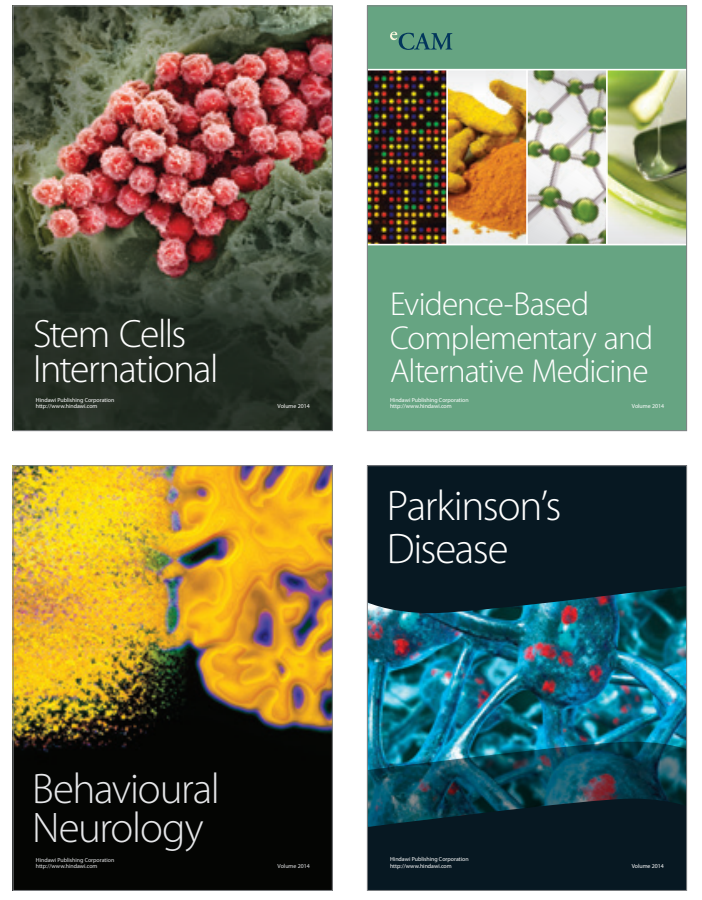
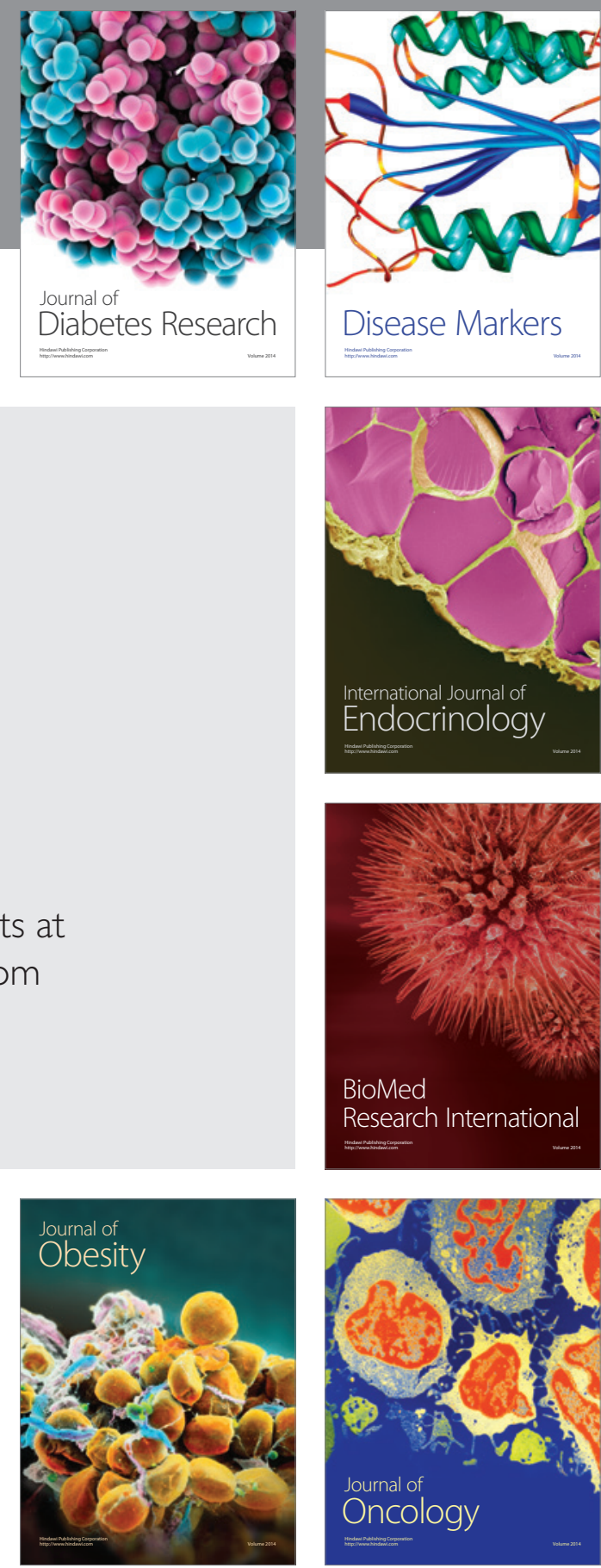

Disease Markers
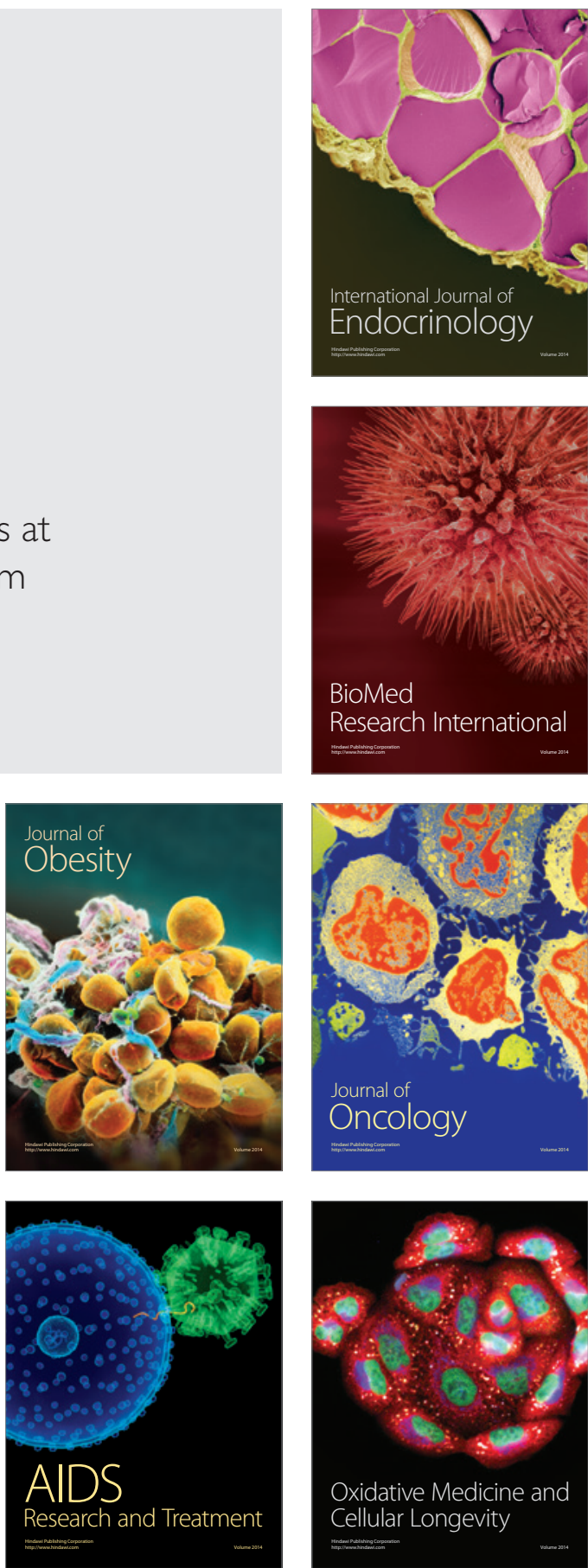